\title{
Complexin Activates Exocytosis of Distinct Secretory Vesicles Controlled by Different Synaptotagmins
}

\author{
Peng Cao, Xiaofei Yang, and Thomas C. Südhof \\ Department of Molecular and Cellular Physiology and Howard Hughes Medical Institute, Stanford University School of Medicine, Stanford, California \\ 94305-5543
}

\begin{abstract}
Complexins are SNARE-complex binding proteins essential for the $\mathrm{Ca}^{2+}$-triggered exocytosis mediated by synaptotagmin-1, $-2,-7$, or -9 , but the possible role of complexins in other types of exocytosis controlled by other synaptotagmin isoforms remains unclear. Here we show that, in mouse olfactory bulb neurons, synaptotagmin-1 localizes to synaptic vesicles and to large dense-core secretory vesicles as reported previously, whereas synaptotagmin-10 localizes to a distinct class of peptidergic secretory vesicles containing IGF-1. Both synaptotagmin-1-dependent synaptic vesicle exocytosis and synaptotagmin-10-dependent IGF-1 exocytosis were severely impaired by knockdown of complexins, demonstrating that complexin acts as a cofactor for both synaptotagmin- 1 and synaptotagmin-10 despite the functional differences between these synaptotagmins. Rescue experiments revealed that only the activating but not the clamping function of complexins was required for IGF-1 exocytosis controlled by synaptotagmin-10. Thus, our data indicate that complexins are essential for activation of multiple types of $\mathrm{Ca}^{2+}$-induced exocytosis that are regulated by different synaptotagmin isoforms. These results suggest that different types of regulated exocytosis are mediated by similar synaptotagmin-dependent fusion mechanisms, that particular synaptotagmin isoforms confer specificity onto different types of regulated exocytosis, and that complexins serve as universal synaptotagmin adaptors for all of these types of exocytosis independent of which synaptotagmin isoform is involved.
\end{abstract}

\section{Introduction}

Four synaptotagmins (Syt1, Syt2, Syt7, and Syt9) function as $\mathrm{Ca}^{2+}$ sensors for synaptic and neuroendocrine vesicle exocytosis (Fernández-Chacón et al., 2001; Sørensen et al., 2003; Xu et al., 2007; Gustavsson and Han, 2009; Schonn et al., 2008) and require as cofactors complexins, which are small proteins that bind to SNARE complexes (McMahon et al., 1995; Reim et al., 2001; Südhof and Rothman, 2009). Complexins perform both activating and clamping functions in exocytosis, and their role is conserved from worms to mammals (Reim et al., 2001; Giraudo et al., 2006, 2008, 2009; Schaub et al., 2006; Tang et al., 2006; Huntwork and Littleton, 2007; Xue et al., 2007, 2009, 2010; Cai et al., 2008; Yoon et al., 2008; Malsam et al., 2009; Maximov et al., 2009; Seiler et al., 2009; Strenzke et al., 2009; Cho et al., 2010; Yang et al., 2010; Hobson et al., 2011; Krishnakumar et al., 2011; Li et al., 2011; Martin et al., 2011). Structurally, complexins contain unstructured $\mathrm{N}$ - and C-terminal sequences that flank an accessory and a central $\alpha$-helix (Bracher et al., 2002; Chen et al., 2002). The

Received Aug. 26, 2012; revised 0ct. 29, 2012; accepted Nov. 27, 2012.

Author contributions:P.C. and T.C.S. designed research;P.C. and X.Y. performed research; P.C. and T.C.S. analyzed data; P.C. and T.C.S. wrote the paper.

This work was supported by National Institutes of Health Grants P50 MH086403 and R01 MH089054 (T.C.S.). We thank Dr. Yea Jin Kaeser-Woo and Dr. Weiping Han for advice and provision of plasmids.

The authors declare no competing financial interests.

Correspondence should be addressed to either of the following: Dr. Thomas C. Südhof, Department of Molecular and Cellular Physiology and Howard Hughes Medical Institute, Stanford University School of Medicine, 265 Campus Drive, Stanford, CA 94305-5543, E-mail: tcs1@stanford.edu; or Dr. Peng Cao at his present address, State Key Laboratory of Brain and Cognitive Science, Institute of Biophysics, Chinese Academy of Sciences, 15 Datun Road, Beijing 100101, China, E-mail: pcao@ibp.ac.cn.

DOI:10.1523/JNEUROSCI.4087-12.2013

Copyright $\odot 2013$ the authors $\quad 0270-6474 / 13 / 331714-14 \$ 15.00 / 0$
$\mathrm{N}$-terminal complexin region is essential for activating synaptic vesicle exocytosis (Xue et al., 2007; Maximov et al., 2009) and for synaptic vesicle priming (Yang et al., 2010), the accessory $\alpha$-helix of complexins is required for clamping synaptic vesicle exocytosis (Maximov et al., 2009), the central $\alpha$-helix binds to SNARE complexes and is necessary for all complexin functions (Tang et al., 2006; Maximov et al., 2009; Martin et al., 2011), and the C-terminal sequence is required for the clamping and priming, but not for the synaptotagmin-activating, functions of complexin (Kaeser-Woo et al., 2012).

To date, all studies of complexin function focused on $\mathrm{Ca}^{2+}$ triggered exocytosis of synaptic vesicles and of large dense-core vesicles (LDCVs) that are controlled by four closely related synaptotagmins (Syt1, Syt2, Syt7, and Syt9; Xu et al., 2007; Schonn et al., 2008; Gustavsson and Han, 2009). However, other types of $\mathrm{Ca}^{2+}$-regulated exocytosis may coexist in neurons in addition to synaptic vesicle and LDCV exocytosis, and other isoforms of synaptotagmin are coexpressed with Syt1, Syt2, Syt7, and/or Syt9 in neurons. Indeed, we recently characterized in olfactory bulb neurons a previously unknown pathway of $\mathrm{Ca}^{2+}$-dependent exocytosis that is selectively controlled by Syt10 instead of Syt1, Syt2, Syt7, and/or Syt9 and that mediates IGF-1 secretion (Cao et al., 2011). Although much is known about complexin function in synaptic and LDCV exocytosis, it is unclear whether complexin also plays a role in other types of exocytosis that are controlled by more distantly related synaptotagmins.

Here, we examined a possible role for complexins in $\mathrm{Ca}^{2+}$ triggered IGF-1 exocytosis in olfactory bulb neurons that is regulated by Syt10 (Cao et al., 2011). We show that the Syt10dependent secretory pathway of IGF-1 is distinct from the LDCV 
pathway of neuropeptide secretion and that complexins are essential for both the Syt1-dependent pathway of neurotransmitter release and the Syt10-dependent pathway of IGF-1 secretion. Thus, complexins represent a conserved component of distinct, parallel, $\mathrm{Ca}^{2+}$-triggered vesicle-fusion reactions controlled by different synaptotagmins.

\section{Materials and Methods}

Culture of olfactory bulb neurons. Olfactory bulb neurons were cultured from newborn mice as described previously (Cao et al., 2011). Briefly, olfactory bulbs were dissected from newborn wild-type mice of either sex (P1$\mathrm{P} 3)$, digested with papain ( $10 \mathrm{U} / \mathrm{ml}$ in $1 \mathrm{mM} \mathrm{CaCl}_{2}$ and $0.5 \mathrm{~mm}$ EGTA) for 20 $\mathrm{min}$ in an incubator, and dissociated with a $1 \mathrm{ml}$ pipette. Dissociated olfactory bulb cells were plated on Matrigel-coated circular glass coverslips (11 $\mathrm{mm}$ diameter) in 24-well dishes and cultured for 14-16 d in vitro (DIV) in 1 $\mathrm{ml}$ of MEM (Invitrogen) supplemented with B27 (Invitrogen), glucose, transferrin, fetal bovine serum, and AraC (Sigma).

Lentiviral constructs and production of lentiviruses. All lentiviral complexin knockdown (KD) and rescue constructs used here were described previously (Maximov et al., 2009; Yang et al., 2010), except for the complexin $\mathrm{KD} /$ rescue constructs used for the pHluorin-Syt10 imaging experiments in which the IRES-GFP was deleted from the standard plasmids. The pHluorin-Syt10 construct was also described previously (Cao et al., 2011). In the myc-Syt10 construct, the myc-epitope sequence was fused to the $\mathrm{N}$ terminus of Syt10 without a linker or a signal peptide. In the IGF-1-Flag construct used, the Flag tag was inserted immediately after the IGF-1 signal peptide (Pfeffer et al., 2009). In the atrial natriuretic factor (ANF)-Venus construct (Burke et al., 1997; obtained from Dr. Weiping Han, Singapore Bioimaging Consortium, Singapore), the cDNA encoding the wild-type atrial natriuretic peptide A precursor is C-terminally fused via a linker (sequence, GGGCCCGGGGGATCCACC) to mVenus. In the phogrin-tdTomato or pHluorin-phogrin constructs (gift from Dr. Weiping Han), the cDNA encoding wild-type phogrin is C-terminally fused via a linker (sequence, GGACCGGTCGCCACC) to tdTomato, and pHluorin is inserted in frame into the KpnI site of the phogrin extracellular coding sequence. All constructs were cloned into lentiviral expression vectors, and lentiviruses were produced essentially as described previously (Maximov et al., 2009; Pang et al., 2010). The lentiviral expression vector (control vector and shRNA-expressing vectors) and three helper plasmids (pRSV-REV, pMDLg/pRRE, and vesicular stomatitis virus $G$ protein-expressing plasmid) were cotransfected into human embryonic kidney 293T (HEK293T) cells (American Type Culture Collection) at 4, 2, 2, and $2 \mu \mathrm{g}$ of DNA per $25 \mathrm{~cm}^{2}$ culture area, respectively. At $48 \mathrm{~h}$ after transfection, the HEK293 cell culture medium was collected and clarified by centrifugation $(500 \times g$ for $5 \mathrm{~min}$ ), and the supernatant containing lentiviral particles was added directly to the medium of cultured olfactory bulb neurons maintained in 24-well plates. For all experiments, olfactory bulb neurons were infected on DIV2-DIV3 and used for electrophysiological analyses on DIV14DIV16 or for IGF-1 secretion measurement on DIV7-DIV8.

Electrophysiological analyses were performed in cultured olfactory bulb neurons on DIV14-DIV16 essentially as described previously (Cao et al., 2011). The bath solution contained the following (in $\mathrm{mm}$ ): 140 $\mathrm{NaCl}, 5 \mathrm{KCl}, 2 \mathrm{MgCl}_{2}, 2 \mathrm{CaCl}_{2}, 10 \mathrm{HEPES}$, and 10 glucose, adjusted to $\mathrm{pH}$ 7.4 with $\mathrm{NaOH}$. The whole-cell intracellular pipette solution contained the following (in mM): $135 \mathrm{CsCl}, 10$ HEPES, 1 EGTA, 1 Na-GTP, 4 Mg-ATP, and $10 \mathrm{QX}-314$, adjusted to $\mathrm{pH} 7.4$ with $\mathrm{CsOH}$. Patch pipettes were pulled from borosilicate glass capillary tubes (catalog \#64-0793; Warner Instruments) using a PC-10 pipette puller (Narishiage). The resistance of pipettes filled with intracellular pipette solution varied between 3.0 and $3.5 \mathrm{M} \Omega$. Presumptive mitral/tufted and granule/periglomerular neurons were identified by microscopy by their size, shape, and visibility of their nuclei (Cheng and Gong, 2009). Mitral neurons were patched and kept in voltage-clamp (at $-70 \mathrm{mV}$ ) whole-cell recording modes using a MultiClamp 700B amplifier (Molecular Devices). After establishment of the whole-cell configuration and equilibration of the intracellular pipette solution with the cytoplasm, the series resistance was compensated to 10-15 M $\Omega$. Recordings with series resistances of $>15$
$\mathrm{M} \Omega$ were rejected. Membrane capacitance $\left(C_{\mathrm{m}}\right)$ and input resistance $\left(R_{\mathrm{m}}\right)$ were measured using Clampex 10 (Molecular Devices). In brief, the Membrane Test Module in Clampex 10 generates a $5 \mathrm{mV}$ square-wave voltage step $(30 \mathrm{~ms})$ in voltage-clamp mode. The $C_{\mathrm{m}}$ is automatically calculated by Clampex 10 based on the waveform of the resulting current transients (Gentet et al., 2000). For the details, see pClamp 10 User Guide (pp 163-166). Evoked synaptic responses were triggered using a standard stimulation current $(90 \mu \mathrm{A}, 1 \mathrm{~ms})$ with a bipolar electrode (CBAEC75 Concentric Bipolar Electrode; outer pole, $125 \mathrm{~mm}$ stainless steel; inner pole, $25 \mathrm{~mm}$ platinum/iridium; FHC) placed at a distance of 100-150 $\mu \mathrm{m}$ from the soma of recorded neurons. The frequency, duration, and magnitude of the extracellular stimulus were controlled with a model 2100 Isolated Pulse Stimulator (A-M Systems) synchronized with Clampex 10 data acquisition software (Molecular Devices). EPSCs were pharmacologically isolated by adding $\mathrm{GABA}_{\mathrm{A}}$ receptor blocker picrotoxin $(50$ $\mu \mathrm{M})$ to the extracellular bath solution. Miniature EPSCs (mEPSCs) were monitored in the presence of tetrodotoxin (TTX; $1 \mu \mathrm{M}$ ) to block action potentials. Data were analyzed using Clampfit 10 (Molecular Devices) and Origin 6.0 (Microcal Software).

Stimulation and measurements of IGF-1 secretion in cultured olfactory bulb neurons. For all experiments, the IGF-1 concentration in the medium was determined with the Quantikine Mouse/Rat IGF-1 ELISA (MG100; R\&D Systems), using serial dilutions of a mouse IGF-1 stock solution $(2 \mu \mathrm{g} / \mathrm{l})$ to generate a standard curve. All IGF-1 secretion experiments were performed at DIV7-DIV8 with $1 \mathrm{~h}$ incubations. Under standard conditions, secretion was stimulated by incubations in either $5 \mathrm{~mm}$ $\mathrm{KCl}$ (control, representing regular culture medium) or $15 \mathrm{~mm} \mathrm{KCl} \mathrm{(de-}$ polarizing medium) in the presence of $1 \mu \mathrm{M}$ TTX; the osmolarity of the 5 $\mathrm{mm} \mathrm{KCl}$ medium was adjusted with $\mathrm{NaCl}$ to that of the $15 \mathrm{~mm} \mathrm{KCl}$ medium. For $\mathrm{Ca}^{2+}$ titration experiments of IGF-1 secretion, neuronal culture medium containing different $\mathrm{Ca}^{2+}$ concentrations was prepared from MEM without calcium (M8167; Sigma-Aldrich) by adding appropriate concentrations of $\mathrm{CaCl}_{2}$, with all other components being identical to those used for regular experiments. To rule out the possibility that synaptic transmission activated by the increase in $\mathrm{KCl}$ may contribute to stimulating IGF-1 secretion, the effect of additions of blockers of major neurotransmitter receptors [ $20 \mu \mathrm{M}$ CNQX, $50 \mu \mathrm{M}$ APV, $0.1 \mathrm{~mm}( \pm)-$ amino-4-carboxy-methyl-phenylacetic acid (MCPG), and $50 \mu \mathrm{m}$ picrotoxin] were analyzed (see Fig. $3 B$ ). To exclude the possibility of unspecified artifacts attributable to the $\mathrm{K}^{+}$stimulation, secretion was also stimulated by inducing membrane depolarization (in the absence of TTX) by field stimulation using a pair of parallel platinum electrodes $(\sim 10 \mathrm{~mm}$ distance) and a $10 \mathrm{~Hz}, 1 \mathrm{~min}$ stimulus train of $100 \mu \mathrm{A}$ pulses (see Fig. $5 C$ ). The position of electrodes was carefully adjusted with a micromanipulator to be $50-100 \mu \mathrm{m}$ above the neuronal culture in the recording chamber, which contained $400 \mu \mathrm{l}$ of extracellular solution. In preliminary experiments, the effectiveness of field stimulation configuration was validated by simultaneous whole-cell recordings. To avoid possible interference by synaptic transmission, synaptic receptor blockers (20 $\mu \mathrm{M}$ CNQX, $50 \mu \mathrm{M}$ APV, $100 \mu \mathrm{M}$ MCPG, and $50 \mu \mathrm{M}$ picrotoxin) were added to the extracellular solution. The culture medium was collected $1 \mathrm{~h}$ after the field stimulation for IGF-1 concentration measurements. Finally, to exclude any possible role for a non- $\mathrm{Ca}^{2+}$ stimulus in IGF-1 secretion, we permeabilized cultured olfactory bulb neurons using digitonin as described previously (Grabner and Fox, 2006). Wild-type cultured olfactory bulb neurons on coverslips were positioned in wells of 24 -well culture plates. The perfusion solution covering the coverslip (250 $\mu \mathrm{l})$ could be rapidly changed with coordinated suction (vacuum) and addition (pipetman) of the perfusion solution. With this experimental paradigm, the neuronal cultures were sequentially treated with (1) perfusion solution ( $140 \mathrm{~mm} \mathrm{NaCl}, 5 \mathrm{~mm} \mathrm{KCl,} 10 \mathrm{~mm}$ HEPES-NaOH, pH 7.4, $2 \mathrm{~mm} \mathrm{MgCl}_{2}, 1 \mathrm{mM} \mathrm{Na}_{2} \mathrm{ATP}, 0 \mathrm{~mm} \mathrm{CaCl}_{2}$, and $100 \mu \mathrm{M} \mathrm{EGTA)} \mathrm{for} 2 \mathrm{~min}$, then (2) the same perfusion solution with $25 \mu \mathrm{M}$ digitonin for $10 \mathrm{~s}$, and then (3) the same perfusion solution without digitonin but with different free $\mathrm{Ca}^{2+}$ concentrations $(0,1,10$, and $100 \mu \mathrm{M})$ for $30 \mathrm{~min}$. In addition, receptor blockers $(20 \mu \mathrm{M}$ CNQX, $50 \mu \mathrm{M}$ APV, $100 \mu \mathrm{M}$ MCPG, and $50 \mu \mathrm{M}$ picrotoxin) and TTX $(1 \mu \mathrm{M})$ were present in the perfusion solution. The relationship between free and total $\mathrm{Ca}^{2+}$ concentrations was calculated using the online calculation tool from Stanford University (http://www. 
A

A
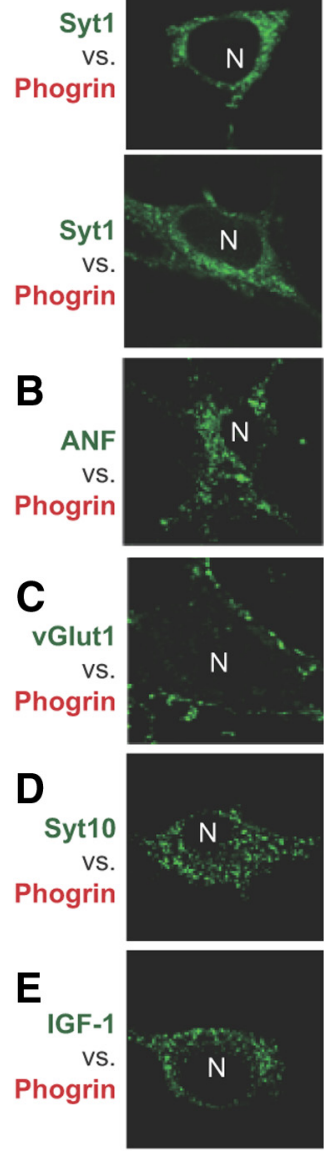

$\mathbf{L}$
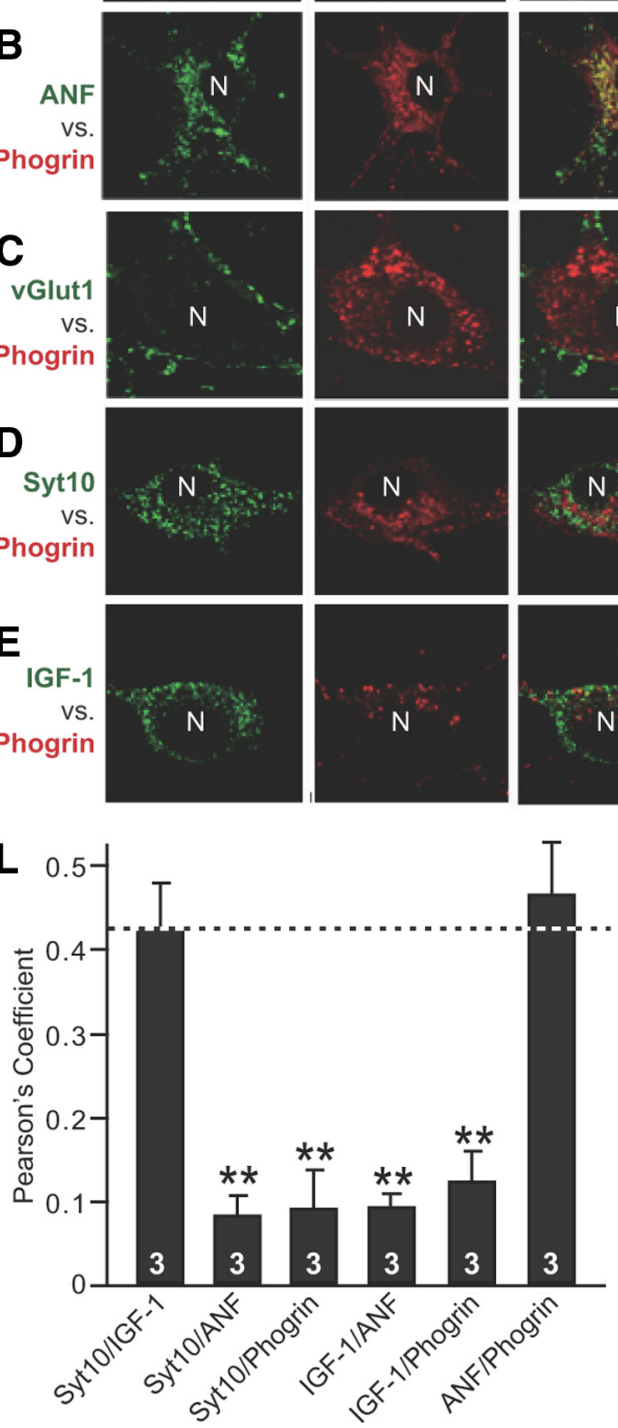

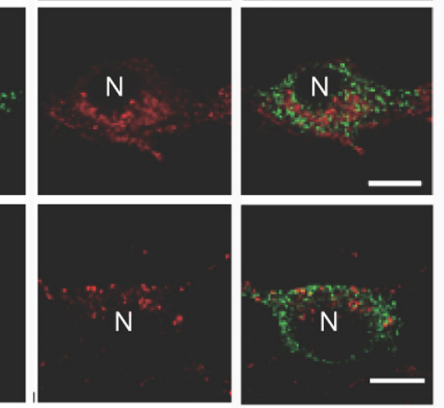

$\mathbf{F}$
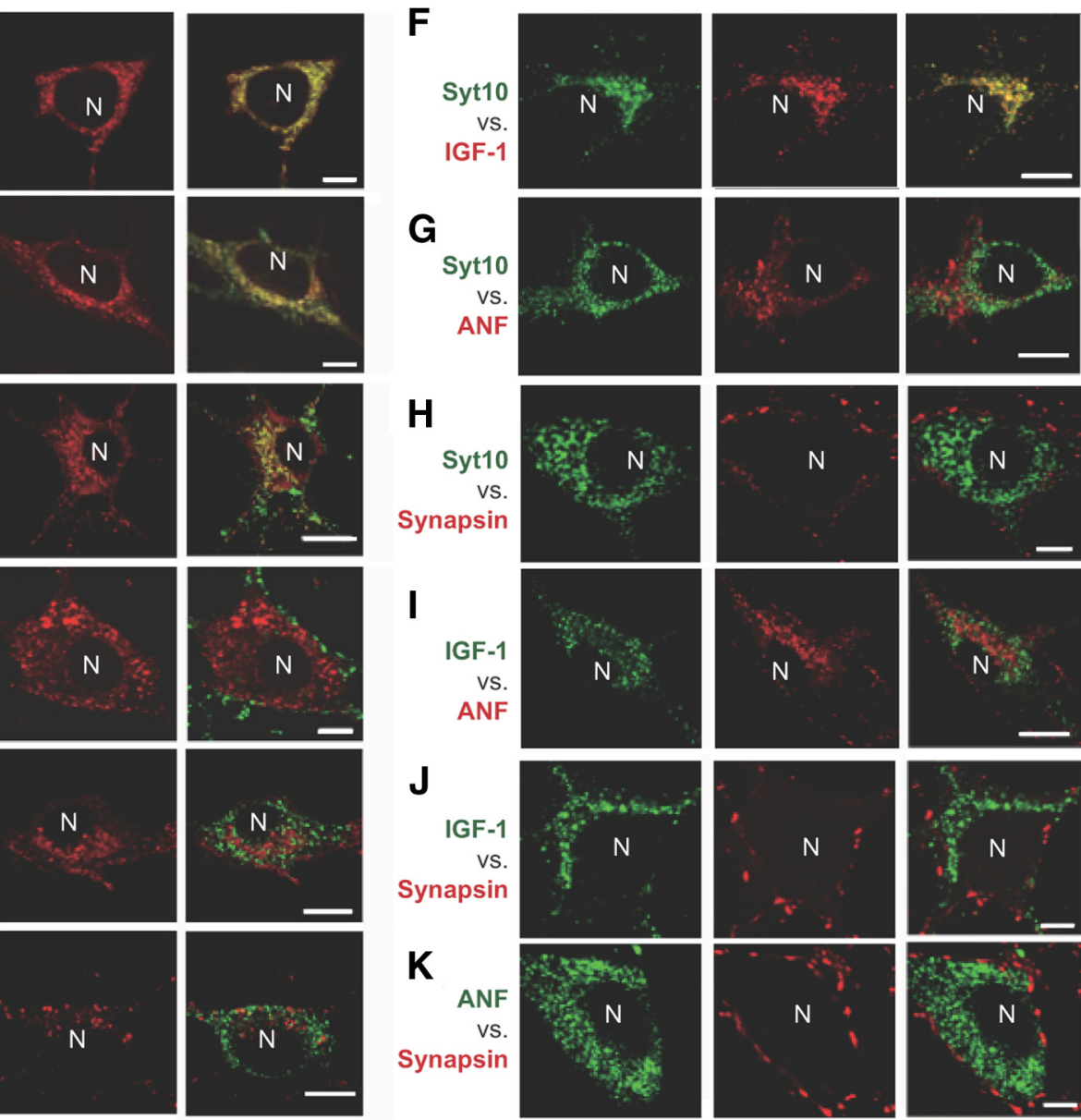

G
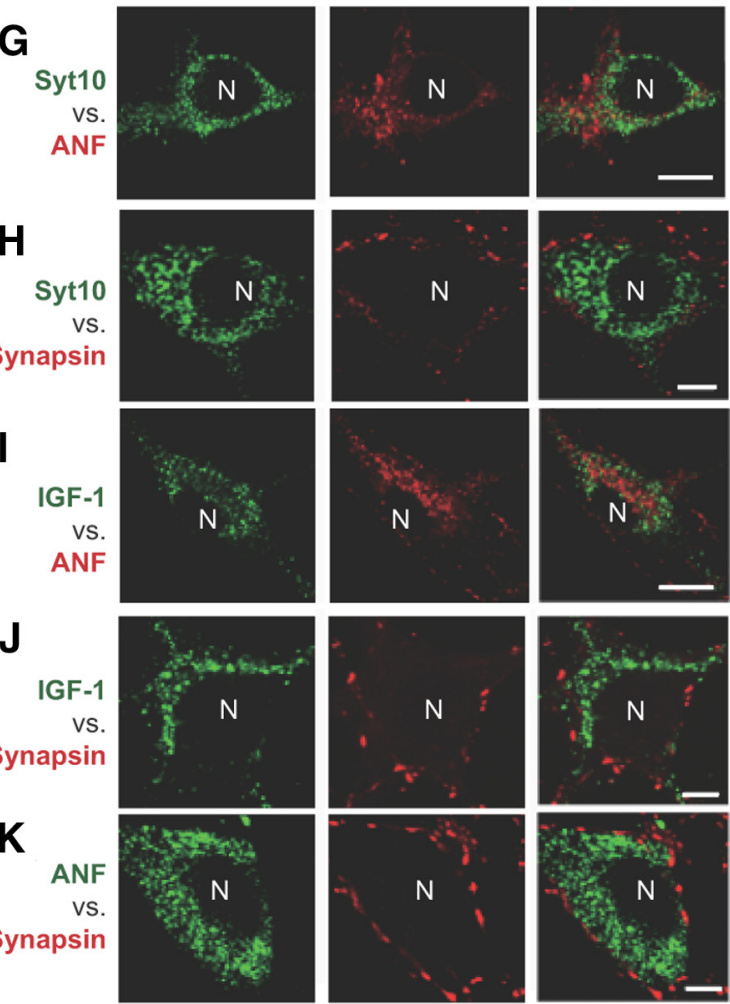

M

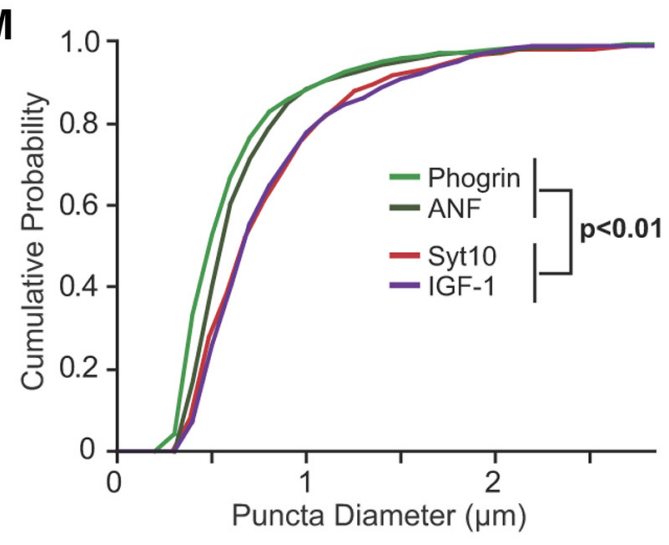

Figure 1. Two distinct peptidergic secretory pathways in olfactory bulb neurons. $\boldsymbol{A}-\boldsymbol{K}$, Representative double-immunofluorescence images of cultured olfactory bulb neurons stained for the indicated endogenous or lentivirally expressed proteins. Single-labeling images are shown on the left and middle and merged images on the right, with coincident labeling in yellow ( $\mathrm{N}$, nucleus). Scale bars, $15 \mu \mathrm{m}$. L, Degree of colocalization of Syt10, IGF-1, ANF, and phogrin in secretory vesicles as calculated with the NIH Image J program using the plug-in JACOP calculator (means \pm SEMs; $n=3$ independent cultures; ${ }^{* *} p<0.01$ by Student's $t$ test; for details, see Materials and Methods). M, Cumulative probability plot of the sizes of Syt10-, IGF-1-, ANF-, and phogrin-containing vesicles as determined by confocal microscopy. Note that Syt 10 and IGF- 1 vesicles and ANF and phogrin vesicles exhibit identical sizes but are statistically significantly different from each other as assessed with the Kolmogorov-Smirnov test $(p<0.01)$.

stanford.edu/ $\sim$ cpatton/CaEGTA-TS.htm). With the perfusion solution used in the experiments $\left(25^{\circ} \mathrm{C}\right.$ temperature, $\mathrm{pH} 7.4$, ionic strength of 0.163 , and $0.1 \mathrm{~mm}$ EGTA), 100,10 , and $1 \mu \mathrm{M}$ free $\mathrm{Ca}^{2+}$ correspond to 200,109 , and $90 \mu \mathrm{M}$ total $\mathrm{Ca}^{2+}$, respectively. After treatments, the perfusion solution was collected for IGF-1 measurements (see Fig. 5D).

Immunocytochemistry of infected neurons. Wild-type cultured olfactory bulb neurons at DIV3 were either single-infected or super-infected with a combination of two lentiviruses encoding pHluorin-Syt10 (Cao et al.,
2011), myc-Syt10, IGF-1-Flag, phogrin-tdTomato, and ANF-Venus (Burke et al., 1997). For immunocytochemistry, cultured olfactory bulb neurons were rinsed with PBS, fixed with 4\% PFA for $20 \mathrm{~min}$ in room temperature, blocked in $4 \%$ goat serum in PBS for $60 \mathrm{~min}$, and then incubated with primary antibodies $(50 \mu \mathrm{l})$ in a damp box for $2 \mathrm{~h}$ at room temperature. The following primary antibodies were used for immunocytochemistry: polyclonal rabbit anti-Synapsin (E028); monoclonal mouse anti-GFP (JL-8; Clontech); monoclonal and polyclonal rabbit 
A
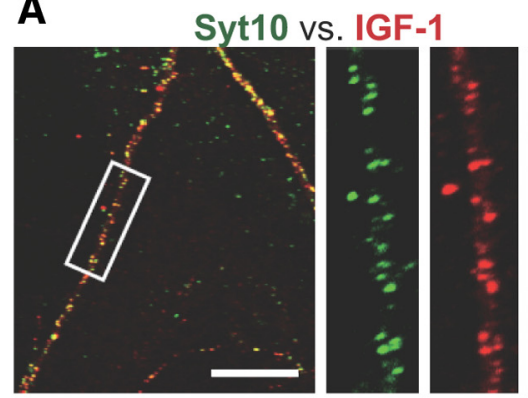

B
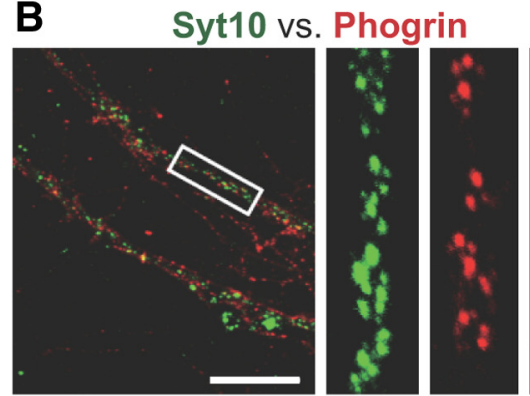

C

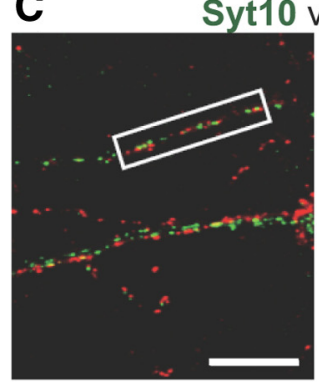

vs. ANF

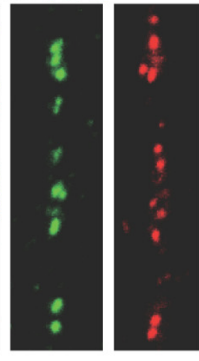

D
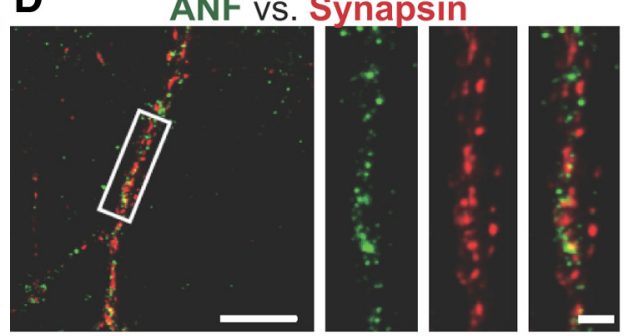

E

ANF vs. Phogrin

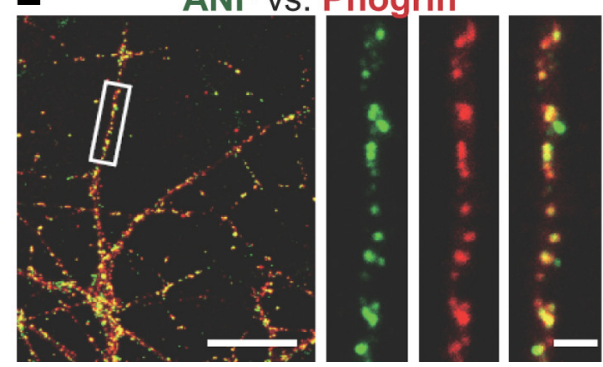

F
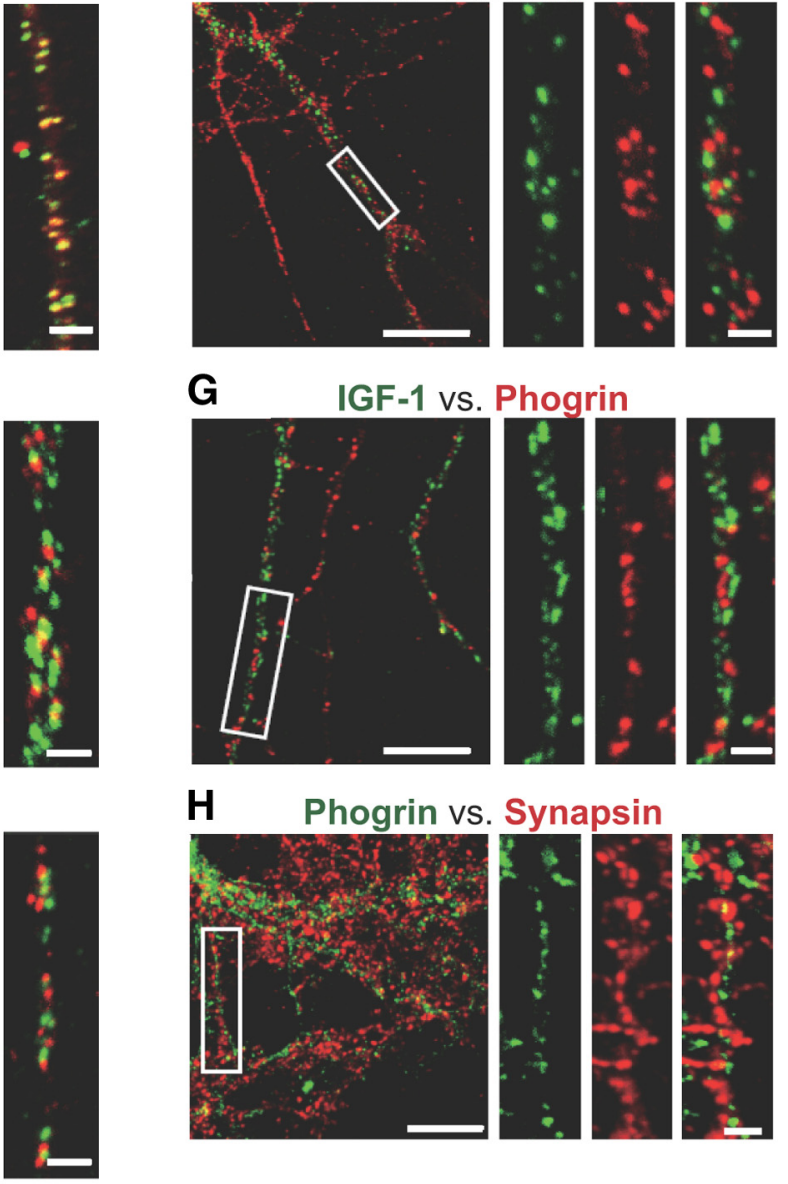

I

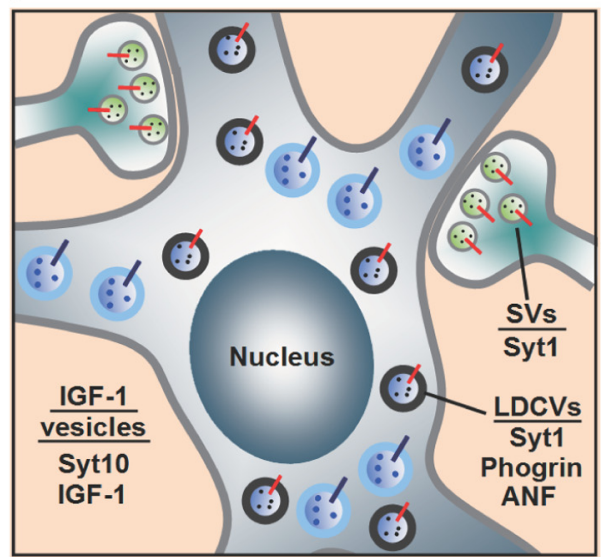

Figure 2. Dendritic non-overlapping localizations of IGF-1-containing vesicles and LDCVs in olfactory bulb neurons. $\boldsymbol{A}-\boldsymbol{H}$, Representative double-immunofluorescence images of dendrites from neurons that coexpress Syt10, IGF-1, ANF, or phogrin. In each set, merged images at intermediate magnification are shown on the left (scale bars, $12 \mu \mathrm{m}$ ), and images of individual labelings at high-magnification as well as merged images are on the right (scale bars, $2.5 \mu \mathrm{m})$. Boxes in the intermediate-resolution images demarcate the origin of the high-resolution images; coincidentlabeling is shown in yellow.I,Schematicdrawing of the three types of secretory vesicles in olfactory bulb neurons: synaptic vesicles (SVs) containing Syt1; LDCVs also containing Syt1; and IGF-1 vesicles containing Sy10.

anti-Flag (Sigma-Aldrich); guinea pig anti-vesicular glutamate transporter 1 (VGluT1; Synaptic Systems); polyclonal rabbit anti-Myc (Sigma-Aldrich); and polyclonal rabbit anti-mCherry (Synaptic Systems). Coverslips were rinsed three times with PBS for 10 min, incubated with fluorescent secondary antibodies (1:500, Alexa Fluor 488-, 546-, or $633-$ labeled highly cross-absorbed goat anti-mouse, goat anti-rabbit, and goat anti-guinea pig antisera; Life Technologies) for $60 \mathrm{~min}$ at room temperature, washed, and mounted with mounting medium (Sigma- 
A

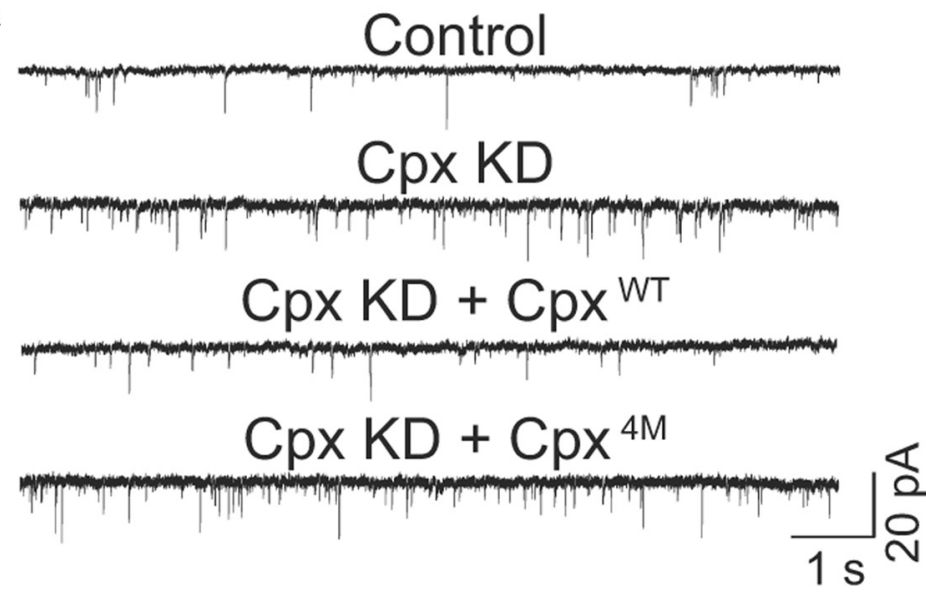

B
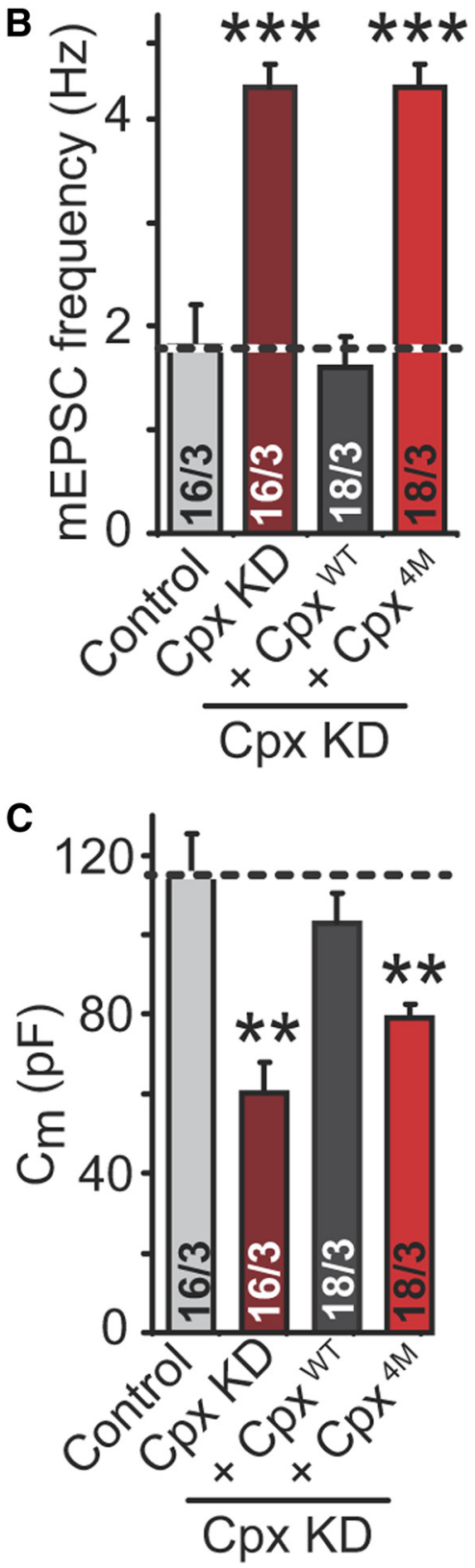
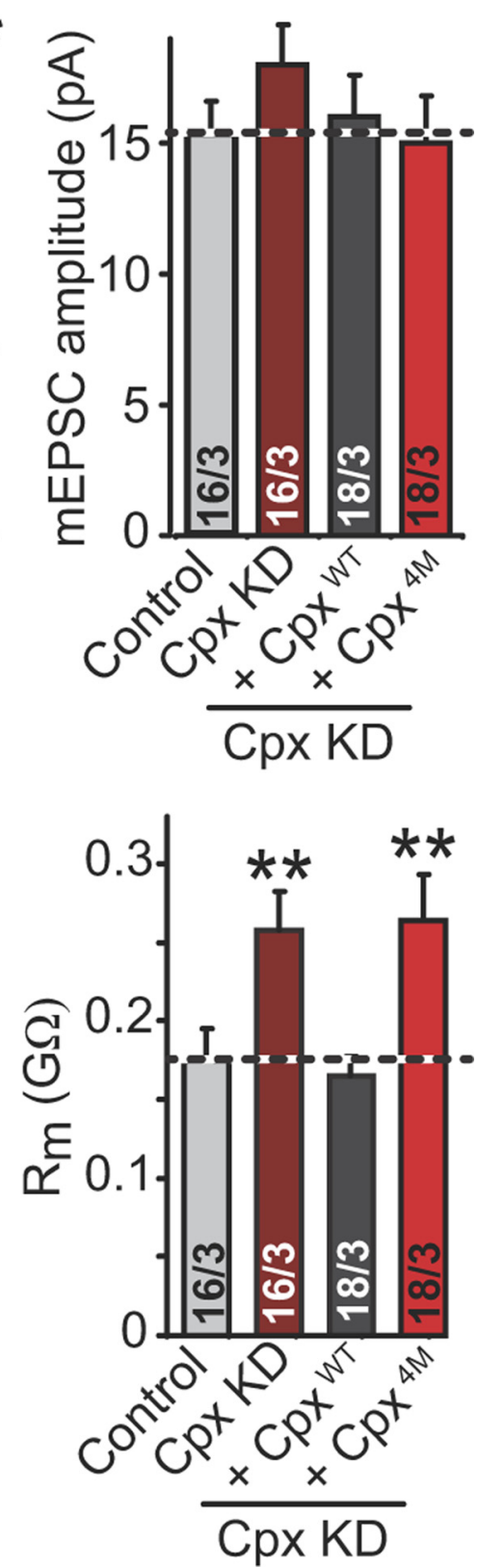

Aldrich). Images were collected with a Leica TCS2 confocal microscope with a $63 \times$ objective. Samples were excited by 488,543 , or 633 $\mathrm{nm}$ lasers in sequential acquisition mode to avoid signal leaking. Identical acquisition settings were applied to all samples of an experiment. Saturation was avoided by monitoring pixel intensity with glowing mode. Confocal images were sequentially recorded with increasing zooms. Normally, a $1 \times$ zoom was used to acquire a global view of the neurons, a $3 \times$ zoom was used to visualize detailed dendritic and axonal structures, and a $5 \times$ zoom was used to visualize the detailed puncta structure within neuronal processes. Colocalization analyses were done using NIH Image J with the plug-in JACoP (http://rsbweb.nih.gov/ ij/plugins/track/jacop.html). Only pictures with a $5 \times$ zoom with detailed puncta structure were used for colocalization analyses. Although the JACoP plug-in can automatically calculate the Pearson's coefficient (PC), the raw PC needs to be corrected by subtracting the background PC (Bolte and Cordelières, 2006), which was obtained by translating one of the images for 15 pixels in both directions. The pictures used for measuring puncta sizes were acquired with a $63 \times$ objective with optical zooming of $\sim 5$, which resulted in image dimensions of $\sim 50$ $\mu \mathrm{m}$. The diameter was analyzed with NIH Image J. In brief, the scale of the pictures was set in NIH Image J based on the physical dimension of the picture recorded by the Leica confocal system. After converting the pictures from red-green-blue color mode to 16-bit mode, the puncta in the pictures were binarized and measured automatically by NIH Image J. To plot the cumulative distribution curves, 300400 puncta for each label were used. Each pair of distribution curves was tested statistically with the Kolmogorov-Smirnov test.

pHluorin-Syt10 live-cell imaging. Cultured olfactory bulb neurons coinfected with pHluorin-Syt10 and complexin KD lentiviruses at DIV2-DIV3 were imaged at DIV14-DIV16. Chambers containing a coverslip with cultured neurons were continuously perfused at $5 \mathrm{ml} /$ min with Tyrode's solution (in mM: $140 \mathrm{NaCl}$, $5 \mathrm{KCl}, 5.5$ glucose, $2 \mathrm{CaCl}_{2}, 2 \mathrm{MgCl}_{2}$, and 20 $\mathrm{mm}$ HEPES-NaOH, pH 7.4). Imaging experiments started with perfusing Tyrode's solution containing $50 \mathrm{mM} \mathrm{NH}_{4} \mathrm{Cl}$ and $90 \mathrm{~mm} \mathrm{NaCl}$ in-

presumptive mitral/tufted neurons in the presence of TTX (1 $\mu \mathrm{M})$ and picrotoxin $(50 \mu \mathrm{M})$. Neurons were infected at DIV2DIV3 with control lentivirus expressing GFP only (Control) or with lentivirus expressing the complexin shRNAs plus GFP only (Cpx KD), GFP together with wild-type complexin-1 ( $\left(\mathrm{px}{ }^{\mathrm{WT}}\right)$, or GFP together with 4M-mutant complexin- $1\left(\mathrm{Cpx}^{4 \mathrm{M}}\right)$ that is unable to bind to SNARE complexes; neurons were analyzed at DIV14-DIV16. C, $C_{\mathrm{m}}$ (left) and $R_{\mathrm{m}}$ (right) measurements of mitral neurons from the same experiment as described in $\boldsymbol{A}$ and $\boldsymbol{B}$. Data shown in $\boldsymbol{B}$ and $\boldsymbol{C}$ are means \pm SEMs; numbers of neurons/independent cultures analyzed are depicted in the bars. Statistical significance was analyzed by Student's $t$ test comparing all samples with the control, with ${ }^{* *} p<0.01$ and ${ }^{* * *} p<0.001$

Figure 3. Complexin $K D$ activates spontaneous release and alters the electrical properties of olfactory bulb neurons. $\boldsymbol{A}, \boldsymbol{B}$, Sample traces $(\boldsymbol{A})$ and summary graphs of the frequency $(\boldsymbol{B}$, left) and amplitude $(\boldsymbol{B}$, right) of spontaneous mEPSCs recorded from 
A
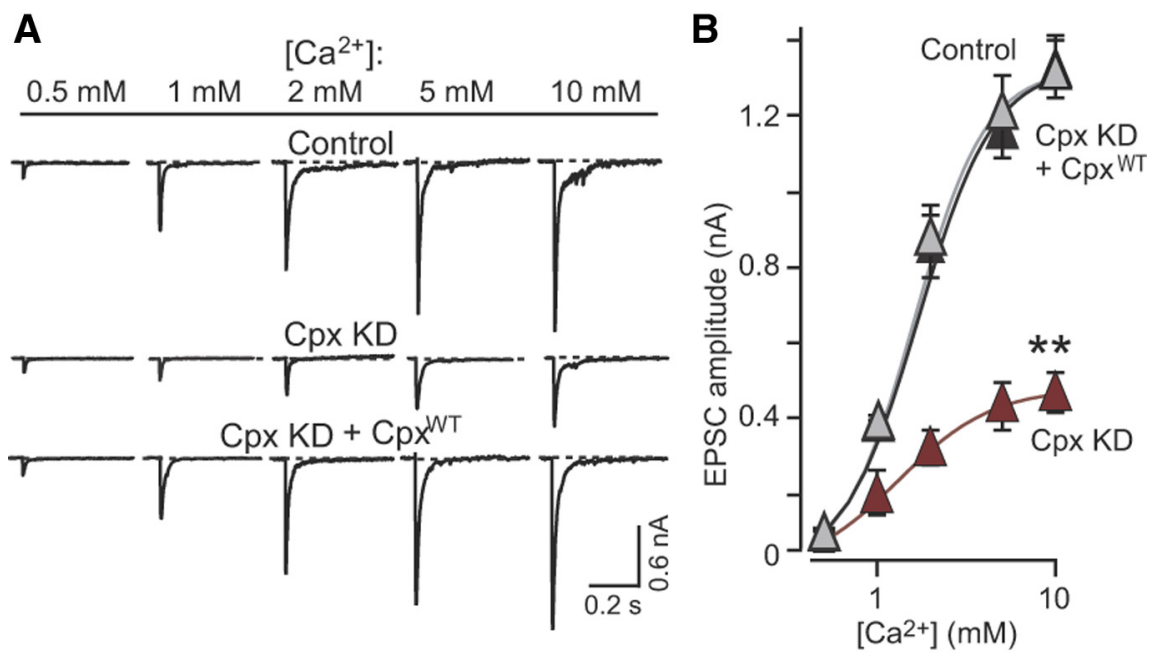

B
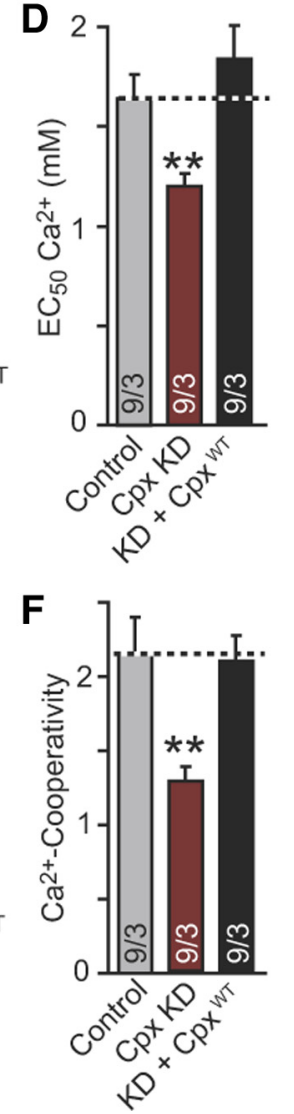

D 2

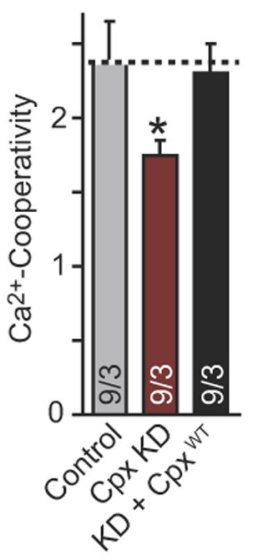

$\mathbf{E}$

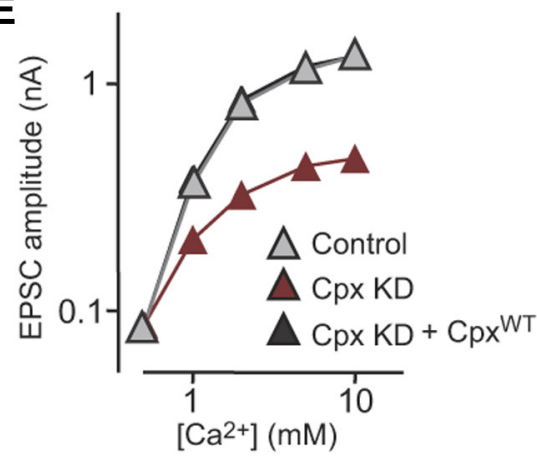

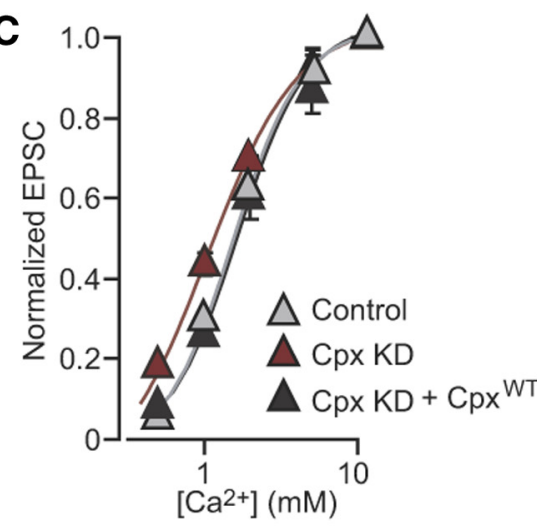

Figure 4. $\mathrm{Ca}^{2+}$ dependence of synaptic vesicle exocytosis in complexin KD neurons. A, Sample traces of AMPA-receptormediated EPSCs evoked by isolated action potentials at the indicated concentrations of extracellular $\mathrm{Ca}^{2+}$. EPSCs were recorded in control neurons and complexin KD neurons without ( $(p x)$ KD) and with rescue with wild-type complexin ( $\left.(p x) K D+C p x{ }^{W T}\right)$ obtained as described for Figure 3. B. Summary plots of the $\mathrm{Ca}^{2+}$ dependence of the amplitude of evoked EPSCs in neurons depicted in $\boldsymbol{A}$. C, Summary plots of the normalized evoked EPSC amplitude recorded at the indicated concentrations of extracellular $\mathrm{Ca}^{2+}$ in control neurons, (px KD neurons, and Cpx KD neurons with expression of wild-type complexin-1 (KD + $\left.\mathrm{Cpx}{ }^{\mathrm{WT}}\right)$. D, Apparent $\mathrm{Ca}^{2+}$ affinity (left; measured as the $\mathrm{EC}_{50}$ for extracellular $\mathrm{Ca}^{2+}$ ) and $\mathrm{Ca}^{2+}$ cooperativity (right) of evoked EPSCS, calculated as described previously (Fernandez-Chacon et al., 2001) by individual Hill-function fits to data from multiple independent $\mathrm{Ca}^{2+}$ titration experiments shown in $\boldsymbol{A}$ and $\boldsymbol{B}$. $\boldsymbol{E}$, Summary double-logarithmic plots of the evoked EPSC amplitude recorded at the indicated concentrations of extracellular $\mathrm{Ca}^{2+}$ in control neurons, Cpx KD neurons, and $\mathrm{Cpx}$ KD neurons with expression of wild-type complexin-1 $\left(\mathrm{KD}+\left(\mathrm{px}^{\mathrm{WT}}\right) \cdot \boldsymbol{F}_{,} \mathrm{Ca}^{2+}\right.$ cooperativity of evoked EPSCs, calculated with Rahamimoff's method (Dodge and Rahamimoff, 1967), using values obtained at 5 and $1 \mathrm{~mm}\left[\mathrm{Ca}^{2+}\right]$. Data shown are means $\pm \mathrm{SEMs}$; numbers of cells/independent cultures analyzed are depicted in the bars. Statistical significance was assessed by two-way ANOVA [in B, Cpx KD without ( $p<$ 0.01 ) and with wild-type rescue $(p>0.1)$ were compared with control] or by Student's $t$ test (in $D$, C $p x$ KD without and with C $p x$ WT rescue neurons were compared with control neurons; $\left.{ }^{*} p<0.05 ;{ }^{* *}<0.01\right)$.

stead of $140 \mathrm{~mm} \mathrm{NaCl}$ to visualize all pHluorin-Syt 10 containing vesicles in a mitral/tufted neuron. After washout of $\mathrm{NH}_{4} \mathrm{Cl}$ by perfusion of regular Tyrode's solution, the chamber was superfused with depolarizing Tyrode's solution containing $15 \mathrm{~mm} \mathrm{KCl}$ and $130 \mathrm{~mm} \mathrm{NaCl}$ instead of $5 \mathrm{~mm} \mathrm{KCl}$ and $140 \mathrm{~mm} \mathrm{NaCl}$, followed again by a washout superfusion period with regular Tyrode's solution. Mitral cells were imaged with a water-immersion objective $(40 \times)$ in a Carl Zeiss confocal imaging system at room temperature. Sequential time-lapse images $(512 \times 512)$ acquired at $4 \mathrm{~s}$ intervals were used to analyze the dynamics of pHluorin-Syt10 in response to $\mathrm{NH}_{4} \mathrm{Cl}$ and membrane depolarization. The image analysis for pHluorin-Syt10 live-cell imaging was done with Carl Zeiss Software ZEN. A $4 \times 4$ pixel region of interest (ROI) was centered on individual pHluorin-Syt10 puncta in the raw images. The built-in measurement module in ZEN software automatically measured the averaged fluorescence intensity within ROI as a function of time. The exocytosis of a pHluorin-Syt10 puncta was quantified by the change of fluorescence $(\Delta F)$ before and after solution perfusion divided by the initial fluorescence $\left(F_{0}\right)$, in which $F_{0}$ is the average fluorescence in the first four frames before onset of stimulus. The image analysis did not involve any thresholding. The averaged fluorescence intensity of an ROI would be completely distorted after thresholding because it would make the pixels on the images either black (intensity, 0) or white (intensity, 255).

Statistical analyses. All experiments were performed in a blinded manner, i.e., the experimenter was unaware of the precise manipulation to which a sample had been subjected. At least three independent cultures for each type of experiment were performed. Statistical comparisons were made using Student's $t$ test or two-way ANOVA as indicated.

\section{Results}

Olfactory bulb neurons contain at least two distinct classes of peptidergic vesicles

The selective requirement for Syt10 but not Syt1 in IGF-1 exocytosis suggested that IGF-1 vesicles containing Syt10 (Cao et al., 2011) are distinct from LDCVs containing Syt1 (Walch-Solimena et al., 1993). However, the neuropeptide-like structure and $\mathrm{Ca}^{2+}$-dependent secretion of IGF-1 by olfactory bulb neurons cast doubt on this notion, because it would suggest the unexpected conclusion that a neuron can express two different types of peptidergic secretory vesicles. Thus, we examined whether markers for LDCVs and IGF-1-containing vesicles localize to the same or different vesicles in cultured olfactory bulb neurons. In these neurons, we primarily analyzed glutamatergic mitral and tufted neurons that can be easily distinguished from the significantly smaller 
GABAergic granule and periglomerular neurons. As markers for LDCVs, we used Syt1, the neuropeptide ANF, and the intrinsic membrane protein phogrin (Zahn et al., 2001; Wasmeier et al., 2005), and as markers for IGF-1-containing vesicles, we used Syt10 and IGF-1 (Cao et al., 2011).

We first expressed tagged phogrin in cultured olfactory bulb neurons via a lentivirus and analyzed the relative distributions of endogenous Syt1 with respect to phogrin. We observed a complete colocalization of Syt1 with phogrin in the cell body of the neurons (Fig. 1A), whereas presynaptic terminals contained only Syt 1 but not phogrin (data not shown). Next, we compared the relative localizations of lentivirally expressed, tagged phogrin to that of ANF, Syt10, and IGF-1, or of the endogenous synaptic markers vGluT1 or synapsin. The vesicular localization of ANF overlapped with that of phogrin in both the neuronal soma (Fig. 1B) and their dendrites (Fig. 2E). The synaptic vesicle marker vGluT1 was not observed in somatic vesicles in the neurons (Fig. 1C), nor was synapsin colocalized with phogrin vesicles in dendrite (Fig. $2 H$ ). Importantly, like phogrin, we found that Syt10 and IGF-1 were also present in somatic (Fig. $1 D, E$ ) and dendritic (Fig. $2 B, G$ ) vesicles that, however, were different from the vesicles containing phogrin.

The phogrin localization experiments suggest that ANF-containing LDCVs also contain Syt 1, but that IGF-1 and Syt 10 are present on separate vesicles. To confirm this conclusion, we compared the relative localization of Syt10 with that of IGF-1, ANF, and synapsin. We detected a complete overlap in the localizations of Syt 10 and IGF-1 (Figs. 1F, 2A) but no overlap between Syt 10 and ANF (Figs. 1G, 2C) or synapsin (which is specific for synaptic vesicles; Fig. 1 H; Cao et al., 2011). Accordingly, we also found no overlap in the localizations of IGF-1 and either ANF (Figs. $1 I, 2 F$ ) or synapsin (Fig. $1 J$ ) or of ANF and synapsin (Figs. $1 K, 2 D$ ). The relative degree of colocalization of different markers in independent experiments was quantified using PC, unequivocally demonstrating that the soma of cultured olfactory bulb neurons contains two different classes of peptidergic vesicles (Fig. 1L). As assayed by light microscopy, ANFand phogrin-containing LDCVs are significantly smaller than Syt 10- and IGF-1-containing vesicles (Fig. 1M). Thus, olfactory bulb neurons produce two separate classes of peptidergic secretory vesicles, LDCVs containing Syt1 and even larger secretory vesicles containing Syt10 and IGF-1 (Fig. 2I).

\section{Synaptic vesicle exocytosis requires complexins}

Because the role of complexin in synaptic vesicle exocytosis and neurotransmitter release has not been investigated previously in
B
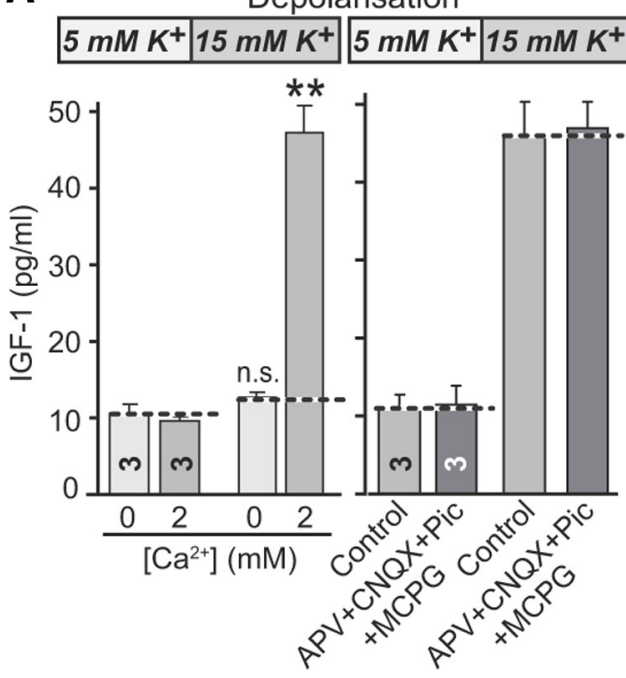

C

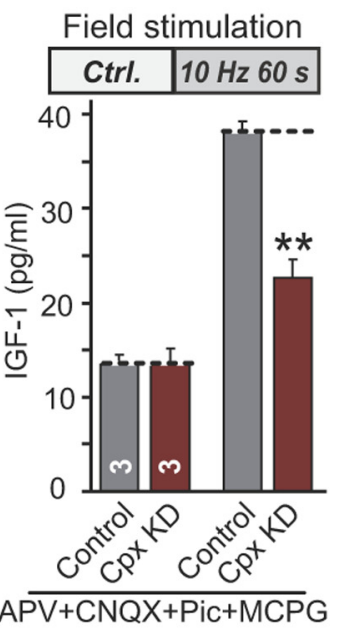

Depolarisation

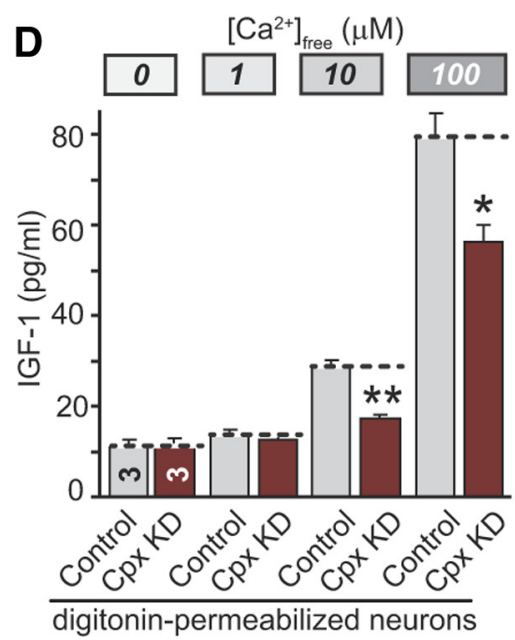

digitonin-permeabilized neurons

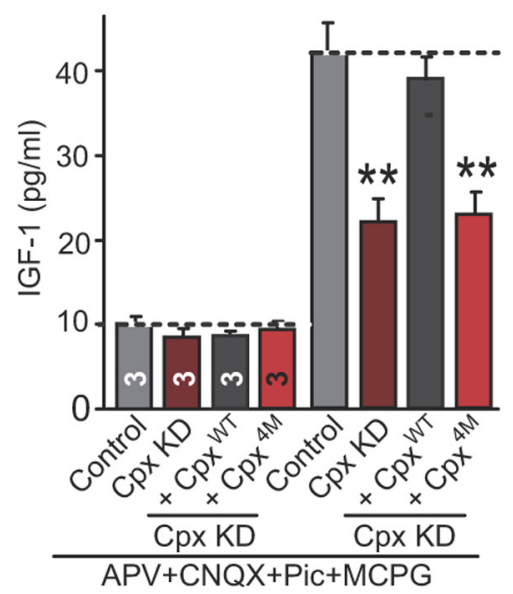

Complexin KD impairs $\mathrm{Ca}^{2+}$-triggered IGF-1 exocytosis. $\boldsymbol{A}$, Characterization of IGF-1 secretion induced by $15 \mathrm{mmK}^{+}$ summary graph) or in regular $2 \mathrm{~mm} \mathrm{Ca}^{2+}$ medium lacking (control) or containing the indicated blockers of all major neurotransmitter receptors [20 $\mu \mathrm{M}$ CNQX, $50 \mu \mathrm{M}$ APV, $50 \mu \mathrm{m}$ picrotoxin (Pic), and $0.1 \mathrm{~mm} \mathrm{MCPG].} \boldsymbol{B}$, Measurements of IGF-1 secretion by cultured olfactory bulb neurons without or with complexin KD (Cpx KD) and/or rescue with wild-type (Cpx ${ }^{\text {WT }}$ ) or mutant (Cpx $\left.{ }^{4 M}\right)$ complexin. Secretion was measured after incubation with control medium containing $5 \mathrm{~mm} \mathrm{~K}^{+}$or depolarizing medium containin the presence of the neurotransmitter receptor antagonists described in $\boldsymbol{A}$, as well as of TTX. $\boldsymbol{C}$, Measurements of IGF- 1 secretion from control and complexin KD olfactory bulb neurons induced by electrical field stimulation in the presence of blockers of $\mathrm{a}^{2+}$ for $10 \mathrm{~s}$ (for details, see Materials and Methods; Grabner and Fox, 2006) and then incubated for 30 min in perfusion solution ontaining the indicated concentrations of free $\mathrm{Ca}^{2+}$, followed by measurements of IGF-1 in the medium. Data shown are means \pm SEMs from three independent cultures. Statistical significance was assessed by Student's $t$ test comparing all samples with the control $\left({ }^{*} p<0.05 ;{ }^{* *} p<0.01\right)$.

olfactory bulb neurons, we examined the role of complexin in synaptic vesicle exocytosis in olfactory bulb neurons using complexin KD experiments. As described previously for cortical neurons (Maximov et al., 2009), we infected cultured olfactory bulb neurons with lentiviruses encoding only EGFP (control), EGFP together with shRNAs suppressing complexin-1 and -2 expression, or EGFP together with the complexin shRNAs and various rescue proteins.

Recordings of spontaneous mEPSCs in mitral/tufted neurons revealed that, as in cortical neurons (Maximov et al., 2009; Yang et al., 2010), the complexin KD produced a more than twofold increase in mEPSC frequency without significantly altering the 
A
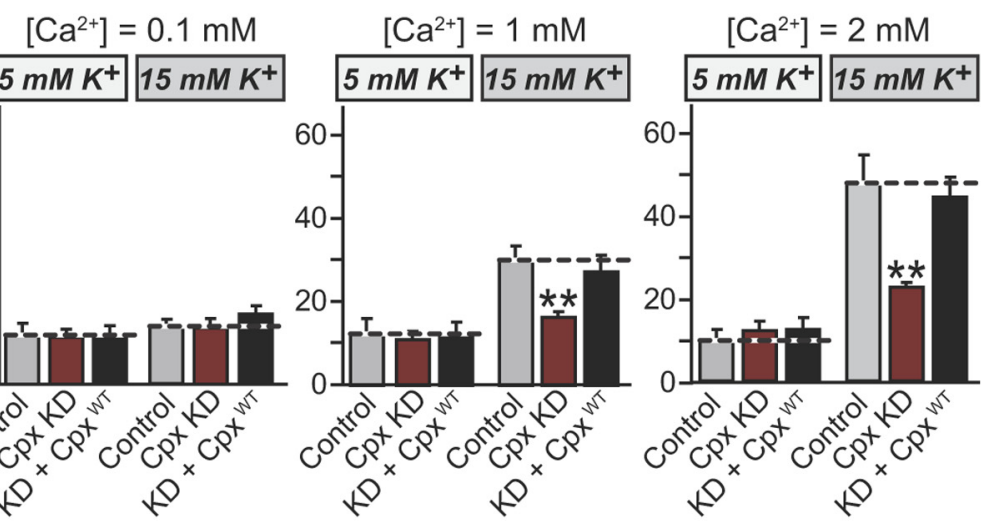

$\left[\mathrm{Ca}^{2+}\right]=5 \mathrm{mM}$
$5 \mathrm{mM} \mathrm{K}^{+} 15 \mathrm{mM} \mathrm{K}^{+}$
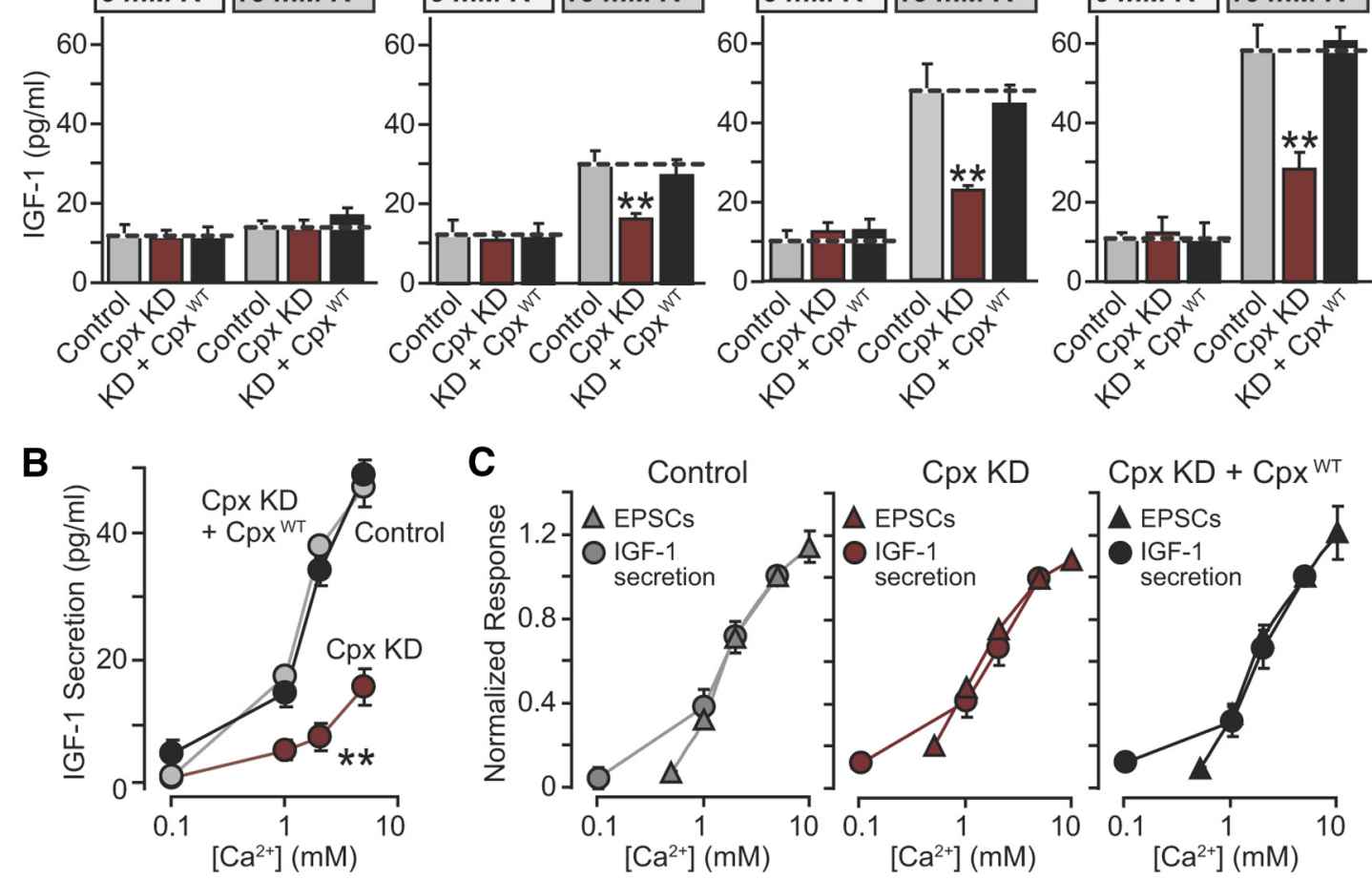

Figure 6. $\mathrm{Ca}^{2+}$ dependence of IGF-1 vesicle exocytosis in complexin KD (Cpx KD) neurons. $A$, Measurements of the IGF-1 concentration in the medium after $1 \mathrm{~h}$ incubation at the indicated concentrations of extracellular $\mathrm{Ca}^{2+}$ in control medium containing $5 \mathrm{~mm} \mathrm{~K}^{+}$or in stimulation medium containing $15 \mathrm{~mm} \mathrm{~K}^{+}$. $\boldsymbol{B}$, Summary plot of the $\mathrm{Ca}^{2+}$ dependence of depolarization-induced

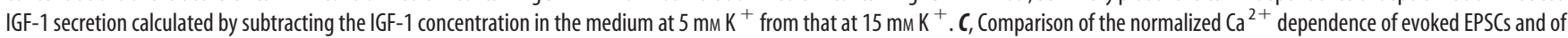
depolarization-induced IGF-1 secretion in control neurons (left), Cpx KD neurons (middle), or Cpx KD neurons expressing wild-type complexin-1 (KD + Cpx WT; right). Data are means \pm SEMs.

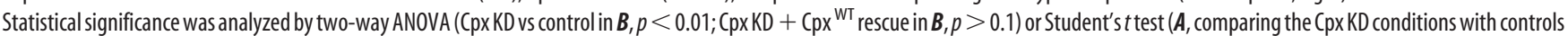
separately for 5 and $15 \mathrm{~mm} \mathrm{~K}^{+}$incubations; $\left.{ }^{* *} \mathrm{p}<0.01\right)$.

mEPSC amplitude (Figs. $3 A, B$ ). This phenotype was rescued by wild-type but not " $4 \mathrm{M}$-mutant" complexin that is unable to bind to SNARE complexes (Tang et al., 2006; Maximov et al., 2009), demonstrating that complexin function requires SNAREcomplex binding. Interestingly, the complexin $\mathrm{KD}$ additionally decreased the $C_{\mathrm{m}}$ and increased the $R_{\mathrm{m}}$ of mitral neurons; again, this phenotype was rescued by wild-type but not $4 \mathrm{M}$-mutant complexin (Fig. 3C). It is notable that the latter complexin $\mathrm{KD}$ phenotype differs from that of cultured cortical neurons in which the complexin KD produces no change in $C_{\mathrm{m}}$ or $R_{\mathrm{m}}$ (Maximov et al., 2009; Yang et al., 2010) but resembles the phenotype of the Syt10 knock-out (Cao et al., 2011). The $C_{\mathrm{m}}$ and $R_{\mathrm{m}}$ increases and decreases with neuronal development, respectively. IGF-1 is a growth factor that promotes neuronal development, such as cell body growth and dendritic arborization. Therefore, $C_{\mathrm{m}}$ and $R_{\mathrm{m}}$ were used as proxy for IGF-1 secretion (Cao et al., 2011).

Next, we monitored the effect of the complexin KD on evoked EPSCs, which we measured in the presence of increasing concentrations of extracellular $\mathrm{Ca}^{2+}$. As described previously in cortical neurons (Yang et al., 2010), the complexin KD produced an approximate threefold decrease in neurotransmitter release in olfactory bulb neurons as assessed by the EPSC amplitude (Figs. $4 A, B)$. Fitting the EPSC amplitude data obtained at different $\mathrm{Ca}^{2+}$ concentrations to a Hill function (Fernández-Chacón et al., 2001) showed that the complexin KD caused a small but significant increase in the apparent $\mathrm{Ca}^{2+}$ affinity and a corresponding decrease in the apparent $\mathrm{Ca}^{2+}$ cooperativity of release (Fig. $4 C, D$ ), again consistent with previous data (Yang et al., 2010). Analysis of the $\mathrm{Ca}^{2+}$ dependence of the EPSC amplitude using a different independent method pioneered by Dodge and Rahamimoff (1967) revealed a similar $\mathrm{Ca}^{2+}$ cooperativity of release in control neurons as the Hill function fittings but an even larger decrease in the apparent $\mathrm{Ca}^{2+}$ cooperativity of release in complexin KD neurons (Fig. 4E,F). Although these analyses do not allow an assessment of the absolute $\mathrm{Ca}^{2+}$ cooperativity of release because they depend on titrations of extracellular $\mathrm{Ca}^{2+}$, they do confirm previous conclusions (Yang et al., 2010) that the complexin KD not only impairs neurotransmitter release but also decreases the apparent $\mathrm{Ca}^{2+}$ cooperativity of neurotransmitter release.

\section{Complexins are essential for IGF-1 exocytosis}

The KD of complexins alters the $C_{\mathrm{m}}$ and $R_{\mathrm{m}}$ in olfactory bulb neurons but not in cortical neurons, and no such changes in $C_{\mathrm{m}}$ and $R_{\mathrm{m}}$ are observed after deletion or KD of Syt1. The changes in $C_{\mathrm{m}}$ and $R_{\mathrm{m}}$ in complexin KD neurons mimic the changes produced by deletion of Syt10, which impairs IGF-1 secretion, thereby leading to a decrease in neuronal size and an increase in electrical resistance (Cao et al., 2011). To test whether the changes in $C_{\mathrm{m}}$ and $R_{\mathrm{m}}$ in complexin $\mathrm{KD}$ neurons are produced by the same mechanism, we examined the effect of the complexin KD on IGF-1 secretion. We stimulated cultured olfactory bulb neurons by mild depolarization with $15 \mathrm{mM} \mathrm{K}^{+}$in the presence of TTX (to block action potentials) and measured the concentration of secreted IGF-1 in the medium. Depolarization of olfactory bulb neurons by $15 \mathrm{mM} \mathrm{K}^{+}$in $\mathrm{Ca}^{2+}$-containing medium induced a large increase in IGF-1 secretion into the medium (Fig. 5A). In contrast, the same depolarization of olfactory bulb neurons in $\mathrm{Ca}^{2+}$. 

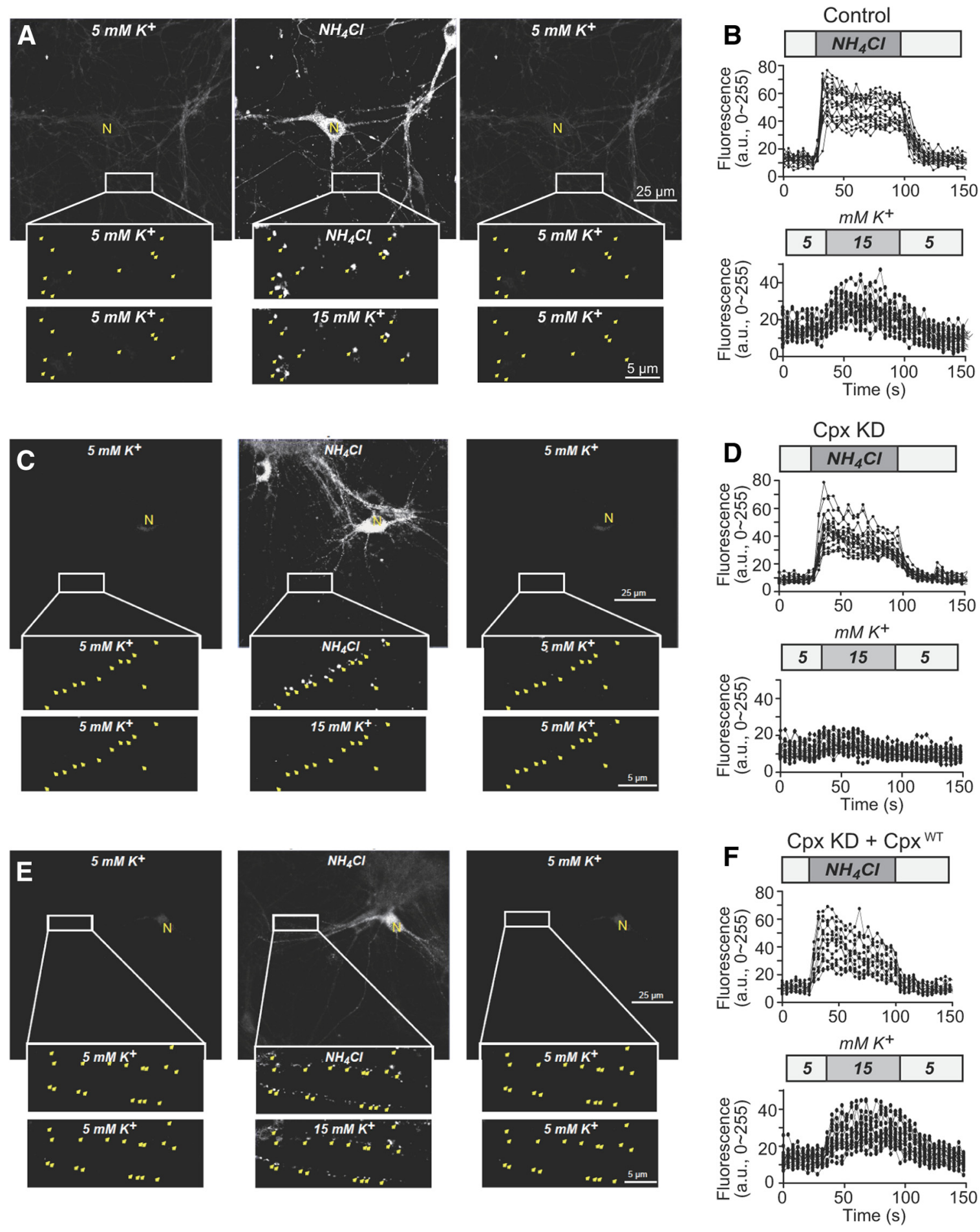

Figure 7. Complexin KD (Cpx KD) impairs Syt10-mediated vesicle exocytosis. $\boldsymbol{A}, \boldsymbol{C}, \boldsymbol{E}$, Representative pHluorin fluorescence images recorded from a control neuron $(\boldsymbol{A})$, a $(\mathrm{pxx}$ KD neuron $(\boldsymbol{C})$, and a $C p x$ KD with Cpx ${ }^{\text {WT }}$ rescue neuron $(\boldsymbol{E})$ expressing pHluorin-tagged Syt10. Neurons were incubated with $50 \mathrm{~mm} \mathrm{NH}_{4} \mathrm{Cl}$ to neutralize all intracellular acidic compartments, thereby visualizing pHluorin-containing compartments, and washed afterward with Tyrode's solution (top and middle rows in $A, C$, and $\boldsymbol{E}$ ). The same neurons were subsequently stimulated with $15 \mathrm{~mm} \mathrm{~K}^{+}$in Tyrode's solution to trigger $\mathrm{Ca}^{2+}$-dependent vesicle exocytosis and finally washed again (bottom rows in $A, C, E$ ). Arrows in yellow indicate pHluorin-Syt10-positive vesicles. $\boldsymbol{B}, \boldsymbol{D}, \boldsymbol{F}, \mathbf{Q u a n t i t a t i o n}$ of the fluorescence intensity of pHluorin-Syt10-containing vesicles in selected neurons ( $\boldsymbol{B}$, control; $\boldsymbol{D},\left(\mathrm{px} \mathrm{KD} ; \boldsymbol{F}\right.$, Cpx KD plus (px ${ }^{\mathrm{WT}}$ rescue) during sequential exposure to $50 \mathrm{~mm} \mathrm{NH}_{4} \mathrm{Cl}$ (top) or $15 \mathrm{~mm} \mathrm{~K}^{+}$ (bottom). Each trace corresponds to one vesicle.

free medium produced no statistically significant increase in IGF-1 secretion, although there was a small nonsignificant increase (Fig. $5 A, p>0.05)$. IGF-1 secretion was not altered by addition of receptor antagonists blocking all neurotransmitter signaling (Fig. $5 A$ ), suggesting that $15 \mathrm{mM} \mathrm{K}^{+}$stimulated IGF-1 secretion directly via depolarization-induced $\mathrm{Ca}^{2+}$ influx and not indirectly via increased synaptic activity.

The complexin $\mathrm{KD}$ significantly reduced $\mathrm{Ca}^{2+}$-dependent IGF-1 secretion but not baseline IGF-1 secretion (Fig. $5 B$ ). As before, this phenotype was rescued by wild-type but not by $4 \mathrm{M}$ - 

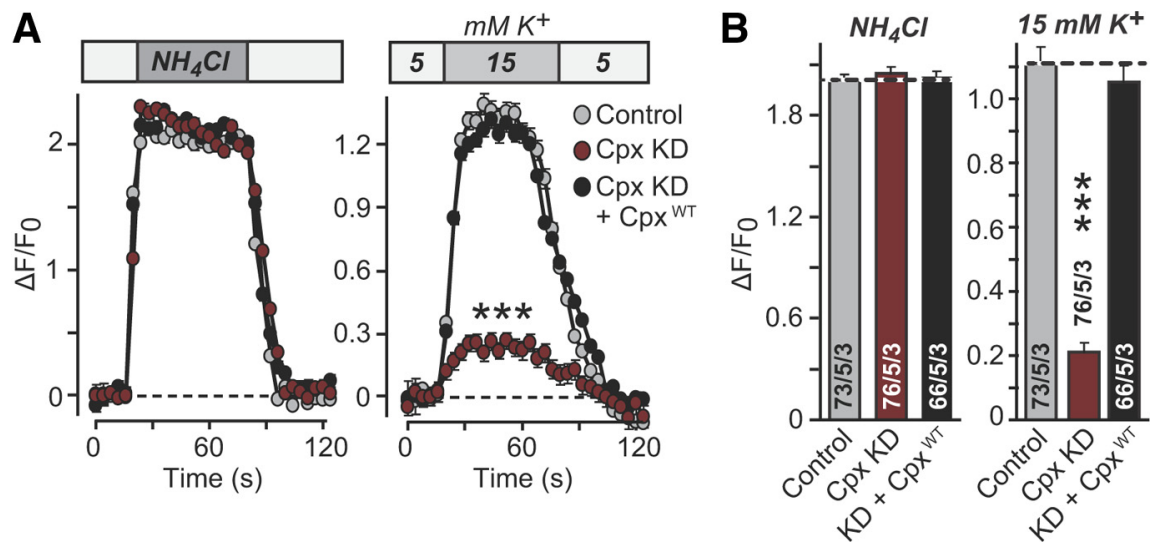

Figure 8. Summary of complexin KD (Cpx KD) effects on Syt10-mediated vesicle exocytosis. $A$, Time course of the average pHluorin-Syt10 fluorescence induced during sequential incubations in $50 \mathrm{~mm} \mathrm{NH}_{4} \mathrm{Cl}$ (left) and $15 \mathrm{~mm} \mathrm{~K}^{+}$(right). Control neurons (gray), Cpx KD neurons (red), and Cpx KD neurons expressing wild-type complexin-1 (Cpx ${ }^{\text {WT }}$, black) —all expressing pHluorinSyt10 — were analyzed. Fluorescence is expressed as the ratio of the stimulus-induced fluorescence change to the starting fluorescence level $\left(\Delta F / F_{0}\right)$. B Average peak fluorescence during incubations with $50 \mathrm{~mm} \mathrm{NH}_{4} \mathrm{Cl}$ (left) or $15 \mathrm{~mm} \mathrm{~K}^{+}$(right) in control neurons, Cpx KD neurons, and Cpx KD neurons expressing wild-type complexin-1 (KD $+\left(\mathrm{px}{ }^{\mathrm{WT}}\right)$. Data in $\boldsymbol{A}$ and $\boldsymbol{B}$ are means \pm SEMs; numbers of pHluorin-Syt10 granules/number of cells/independent cultures analyzed are depicted in the bars of $\boldsymbol{B}$. Statistical significance was assessed in $\boldsymbol{A}$ by two-way ANOVA for the incubations in $\mathrm{NH}_{4} \mathrm{Cl}$ (left; $p>0.1$ for all comparisons) and in $15 \mathrm{~mm}$ $\mathrm{K}^{+}$(right; $p<0.001$ comparing (px KD neurons with control neurons or with (px KD neurons expressing (px ${ }^{\text {WT }}$ ) and in $\boldsymbol{B}$ by Student's $t$ test comparing the C $\mathrm{xx}$ KD conditions with controls ( $\left.{ }^{* * *} p<0.001\right)$.

mutant complexin. Similar to synaptic vesicle exocytosis, the complexin KD only partly blocked $\mathrm{Ca}^{2+}$-induced IGF-1 exocytosis, possibly because the KD efficiency is not $100 \%$ or because complexin is not as essential for $\mathrm{Ca}^{2+}$ triggering of exocytosis as Syt1 (for synaptic vesicle exocytosis) or as Syt10 (for IGF-1 exocytosis).

The impairment in IGF-1 secretion induced by the complexin $\mathrm{KD}$ was independent of the stimulation method used. We observed the same impairment of IGF-1 secretion when we stimulated olfactory bulb neurons electrically by triggering trains of action potentials, which were again elicited in the presence of neurotransmitter receptor blockers to occlude any possible interference produced by synaptic transmission (Fig. 5C). Moreover, to confirm with yet another independent assay that $\mathrm{Ca}^{2+}$ directly induced IGF-1 exocytosis, we assayed IGF-1 exocytosis in cultured olfactory bulb neurons that had been permeabilized with digitonin (Grabner and Fox, 2006). We measured IGF-1 secretion induced by addition of $\mathrm{Ca}^{2+}$ to the permeabilized neurons (Fig. 5D). Again, we observed $\mathrm{Ca}^{2+}$-dependent IGF-1 exocytosis that was partially blocked by the complexin KD. Thus, $\mathrm{Ca}^{2+}$ directly triggers IGF-1 exocytosis - presumably by binding to Syt 10 (Cao et al., 2011) - and complexin is essential for this $\mathrm{Ca}^{2+}$-triggered IGF-1 exocytosis independent of synaptic transmission.

We then asked whether IGF-1 secretion and neurotransmitter release exhibit a similar $\mathrm{Ca}^{2+}$ dependence in olfactory bulb neurons and whether the complexin $\mathrm{KD}$ alters the $\mathrm{Ca}^{2+}$ dependence of these secretory processes in a similar manner. We found that the $\mathrm{Ca}^{2+}$ dependence of IGF-1 secretion and synaptic vesicle exocytosis in olfactory bulb neurons were similar and that the complexin $\mathrm{KD}$ produced an almost identical effect on $\mathrm{Ca}^{2+}$-dependent IGF-1 exocytosis as on neurotransmitter release (Fig. 6A,B). Direct comparison of the $\mathrm{Ca}^{2+}$ concentration dependence of EPSCs and IGF-1 secretion failed to reveal significant differences at intermediate and higher $\mathrm{Ca}^{2+}$ concentrations (Fig. 6C), consistent with the similar $\mathrm{Ca}^{2+}$ affinities of Syt1 and Syt10 (Sugita et al., 2002). It is possible that the relative amounts of neurotransmitter and IGF-1 release differ at low $\mathrm{Ca}^{2+}$ concentrations, but it is difficult to accurately test this possibility because of the low sensitivity of IGF-1 secretion assay that renders precise measurements of low levels of IGF-1 secretion difficult.

\section{Imaging the effect of the complexin KD} on Syt10-mediated exocytosis

To further analyze the impairment in IGF-1 secretion we observed after the complexin $\mathrm{KD}$, we used imaging and directly probed the effect of the complexin KD on Syt10-containing vesicles. We lentivirally expressed pHluorin-tagged Syt10 in cultured olfactory bulb neurons and monitored depolarization-induced exocytosis of Syt10-containing vesicles with fluorescence imaging (Cao et al., 2011). In these experiments, we first exposed the neurons to $50 \mathrm{mM} \mathrm{NH}_{4} \mathrm{Cl}$ to visualize pHluorin-Syt10-containing vesicles, washed out the $\mathrm{NH}_{4} \mathrm{Cl}$, exposed the neurons to $15 \mathrm{mM} \mathrm{K}^{+}$to stimulate $\mathrm{Ca}^{2+}$. induced exocytosis, and finally washed out the $15 \mathrm{M} \mathrm{K}^{+}$solution. All experiments were performed in the presence of $1 \mu \mathrm{M}$ TTX to suppress depolarization-induced network activity that may indirectly induce exocytosis of pHluorin-Syt10-containing vesicles. Using this method, we visualized Syt 10-containing vesicles in dendrites and monitored their depolarization-induced exocytosis under control conditions and after complexin KD without or with rescue (Fig. 7).

Small elevations in the extracellular $\mathrm{K}^{+}$concentration (from 5 to $15 \mathrm{~mm}$ ) rapidly induced $\mathrm{Ca}^{2+}$-dependent exocytosis of Syt 10 containing vesicles in control neurons (Figs. $7 A, B, 8 A, B$ ) but were more than threefold less effective in complexin KD neurons (Figs. 7C,D, 8A,B). Although some rapid exocytosis of Syt10containing vesicles was still observed in complexin $\mathrm{KD}$ neurons, the complexin $\mathrm{KD}$ decreased the overall rate of exocytosis. In contrast, the complexin KD had no effect on the strength of the pHluorin-Syt10 signal produced by $\mathrm{NH}_{4} \mathrm{Cl}$ (Figs. $7 A-D, 8 A, B$ ). The phenotype of the complexin $\mathrm{KD}$ was fully rescued by wildtype complexin (Figs. $7 E, F, 8 A, B$ ), demonstrating that the complexin $\mathrm{KD}$ specifically impaired exocytosis and not vesicle biogenesis. Thus, complexin is directly required for $\mathrm{Ca}^{2+}$ triggered exocytosis of Syt10-containing secretory vesicles in olfactory bulb neurons.

\section{Only the activating function of complexin is required for IGF- 1 exocytosis}

In synaptic exocytosis, complexin functions as both an activator and a clamp (Reim et al., 2001; Tang et al., 2006; Huntwork and Littleton, 2007; Xue et al., 2007, 2009, 2010; Cai et al., 2008; Maximov et al., 2009; Strenzke et al., 2009; Cho et al., 2010; Yang et al., 2010; Hobson et al., 2011; Martin et al., 2011). These functions require distinct complexin sequences. To test which of these complexin functions operate in IGF-1 secretion, we performed rescue experiments with mutants of complexin that selectively disrupt these functions, namely a deletion of the N-terminal 26 complexin residues that blocks its activating but not its clamping function (Maximov et al., 2009), and the "poorclamp" point mutation in the accessory $\alpha$-helix that blocks its clamping but not its activating function (Yang et al., 2010). In addition, we analyzed a mutant that disrupts both complexin functions (the deletion of 

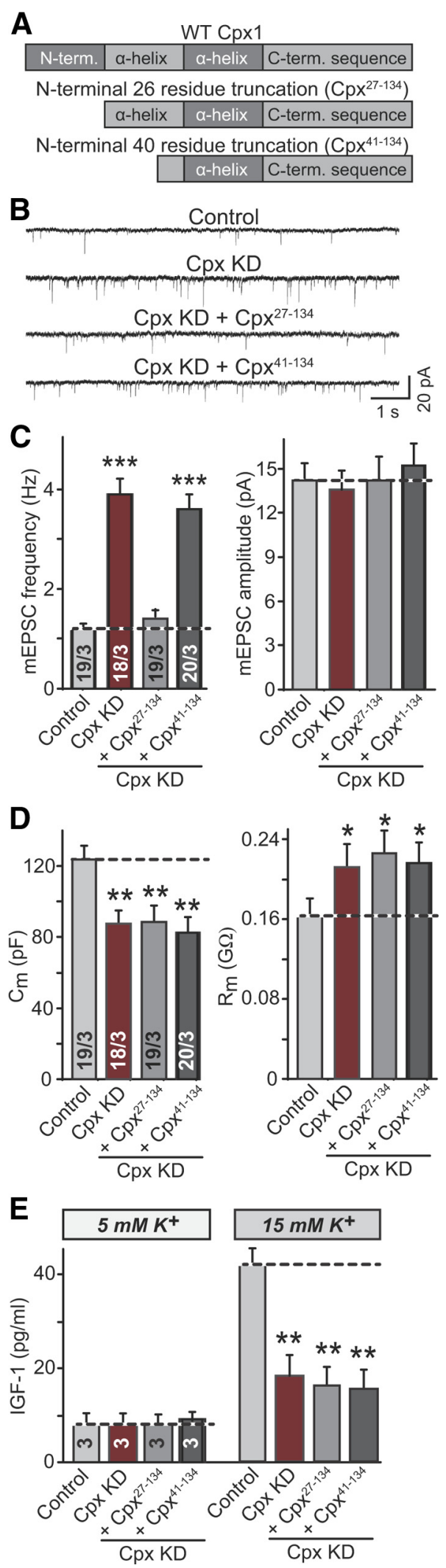

Figure 9. Rescue effects of truncated complexin-1 on synaptic and IGF-1 vesicle exocytosis. $\boldsymbol{A}$, Schematic diagram of wild-type (WT (px) and truncated complexin-1. The two truncation mutants of complexin- 1 were designed to selectively block the complexin-1 activation function [truncation of residues 1-26 $\left(\mathrm{Cpx}^{27-134)}\right)$ ] or both the complexin-1 activation and clamping function [truncation of residues 1-40 ( $\left.\mathrm{px}^{41-134}\right)$; Maximov et al., 2009]. B, C, Sample traces $(\boldsymbol{B})$ and summary graphs $(\boldsymbol{C})$ of the mitral/tufted cell mEPSC frequency (left) and amplitude (right) recorded from mitral/tufted neurons at DIV14 -DIV16. Cultured olfactory bulb neurons the $\mathrm{N}$-terminal 40 complexin residues) and a mutant designed to enhance clamping (the "superclamp" mutant; Giraudo et al., 2009). The poorclamp mutant was generated in complexin-1 by combined substitution of three residues (K26E/L41K/E47K) that were mutated because they align with the synaptobrevin-2 SNARE-motif sequence in a reverse orientation (see Fig. 10A; Yang et al., 2010), suggesting that these residues may promote insertion of the accessory complexin $\alpha$-helix into the SNARE complex during clamping (Giraudo et al., 2009). Mutating these residues was thus predicted to decrease the clamping function of complexin, as confirmed in cultured cortical neurons (Yang et al., 2010).

All of the complexin mutants tested (Figs. 9A, 10A) altered neurotransmitter release in olfactory bulb neurons in a manner similar to their previously observed effects in cortical neurons (Figs. 9B, C, 10 B, C; Yang et al., 2010). Interestingly, the complexin poorclamp mutant not only failed to rescue the increased mEPSC frequency in complexin KD neurons, it even aggravated this increase in a statistically significant manner (Fig. 10C). At the same time, the poorclamp mutant rescued the decrease in evoked release in complexin KD neurons (Yang et al., 2010). The increased mini frequency in neurons expressing the poorclamp complexin mutant could be explained by a dominant-negative effect or by rescue of priming (which is impaired by the complexin KD; Yang et al., 2010) without a change in clamping from the regular $\mathrm{KD}$ condition. Increased priming may render more vesicles ready for spontaneous release and thus indirectly increase the mini rate. In looking back, we previously observed a similar effect of the poorclamp mutant (but not a significant difference) on the mini frequency in cultured cortical neurons (Yang et al., 2010). Cultured olfactory bulb neurons may be more reliable than cultured cortical neurons in revealing this phenotype because it is easier in cultured olfactory bulb neurons to record from specific neuron types (i.e., mitral and tufted neurons).

We next measured the effect of the various complexin mutations on $\mathrm{Ca}^{2+}$-stimulated IGF-1 secretion from olfactory bulb neurons. Using $C_{\mathrm{m}}$ and $R_{\mathrm{m}}$ measurements as a proxy for IGF-1 secretion or using direct IGF-1 secretion measurements, we found that the clamping mutants did not change the baseline level of IGF-1 secretion under control conditions, nor did they later evoke IGF-1 secretion (Fig. 10). This result indicates that complexin-clamped "spontaneous" IGF-1 release does not provide a major contribution to IGF-1 secretion and highlights the greater importance of the activation function of complexin. Indeed, the activation mutants of complexin did not rescue the IGF-1 secretion phenotype (Figs. $9 D, E, 10 D, E$ ), revealing that complexin function in IGF-1 exocytosis completely relies on its role as an activator. It would have been interesting to measure the $\mathrm{Ca}^{2+}$ dependence of IGF-1 secretion with the N-terminal complexin mutants that block its activation function. However, the large decrease in IGF-1 secretion caused by these mutations and the low sensitivity of IGF-1 measurements compared with EPSC measurements make it difficult to accurately determine the $\mathrm{Ca}^{2+}$

were infected with control lentivirus or (px KD lentiviruses expressing GFP only or GFP with N-terminal truncation mutants of complexin-1. D, $C_{\mathrm{m}}$ (left) and $R_{\mathrm{m}}$ (right) of the mitral/tufted neurons examined in $\boldsymbol{B}$ and $\boldsymbol{C}$. $\boldsymbol{E}$, Measurements of IGF-1 secretion by cultured olfactory bulb neurons after incubation in 5 or $15 \mathrm{~mm} \mathrm{~K}^{+}$for $1 \mathrm{~h}$ at DIV7-DIV8. Neurons were infected with lentiviruses as described in $\boldsymbol{B}$ and $\boldsymbol{C}$. Data are means \pm SEMs; numbers of neurons/independent cultures $(\boldsymbol{C}, \boldsymbol{D})$ or cultures $(\boldsymbol{E})$ are depicted in the bars. Statistical significance was assessed by Student's $t$ test, comparing various ( $p x \mathrm{KD}$ conditions with the control condition $\left({ }^{*} p<0.05\right.$; $\left.{ }^{* *} p<0.01 ;{ }^{* * *} p<0.001\right)$. 


\section{A}

rev. Syb2: RKLKAASTEFQSAGAQLADARDDLES WT Cpx1: EKDPDAAKKEEERQEALRQAE EERKA Poorclamp: EE DPDAAKKEEERQEAKRQAE EKRKA Superclamp: EK LPDAAKKFEEAQEALRQAE EERKA Accessory $\alpha$-Helix

B
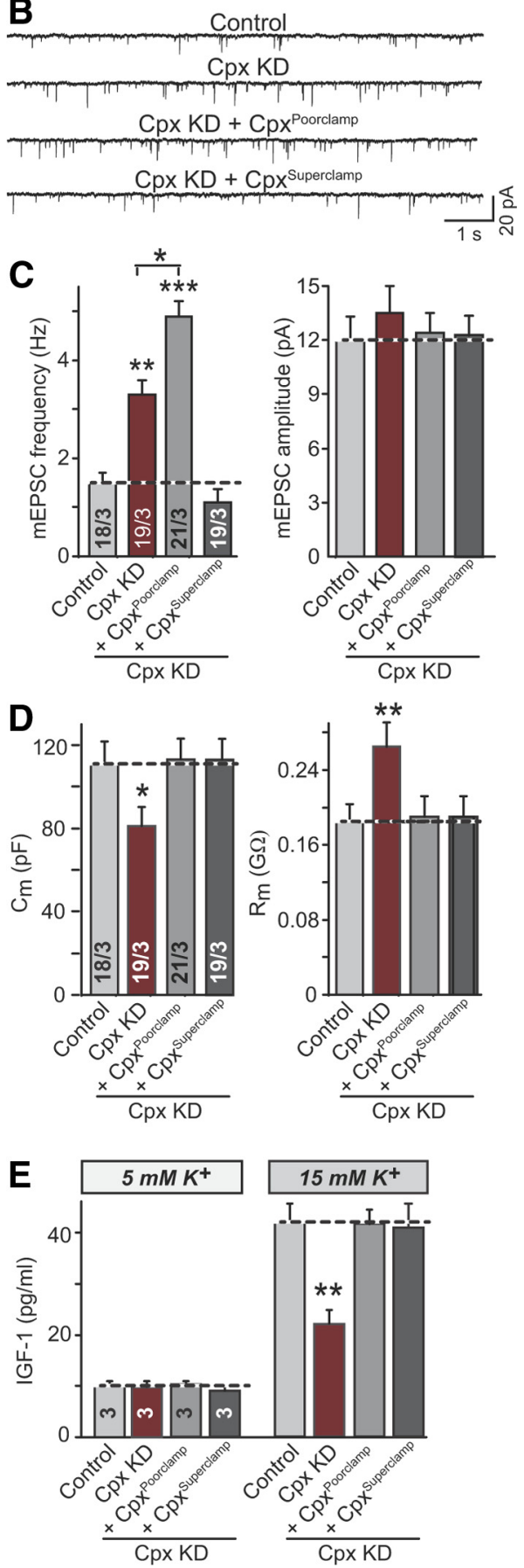

Figure 10. Rescue effects of poorclamp and superclamp complexin-1 mutant on synaptic and IGF-1 vesicle exocytosis. $\boldsymbol{A}$, Alignment of the reverse synaptobrevin-2 (rev. Syb2) sequence (residues 86-61) with the wild-type complexin-1 (WT (px1) sequence (residues 25-50) and the corresponding sequences of the complexin-1 superclamp and poorclamp mutants. Yellow and green shading indicates identical and similar residues in the reverse synaptobrevin- 2 and the wild-type complexin- 1 sequences. Red residues represent mutated amino acids in the superclamp ( $\left(\mathrm{px}^{\text {Superclamp }}\right)$ and poorclamp ( $\left.\mathrm{px}^{\text {Poorclamp }}\right)$ complexin-1 versions. These two complexin-1 mutants were designed to make complexin-1 more or less similar to synaptobrevin-2 (Yang et al., 2010). B, C, Sample traces $(\boldsymbol{B})$ and summary graphs $(\boldsymbol{C})$ of the mitral/tufted cell mEPSC frequency (left) and amplitude (right) recorded from mitral/tufted dependence of the little bit of IGF-1 secretion that is left with these complexin mutants.

\section{Discussion}

The present study asks two fundamental questions. First, does the $\mathrm{Ca}^{2+}$-dependent exocytosis of IGF-1 we described recently in olfactory bulb neurons (Cao et al., 2011) represent a standard pathway of neuropeptide secretion similar to the wellcharacterized pathway of LDCV exocytosis (Winkler and Fischer-Colbrie, 1998), or does it constitute a novel distinct secretory pathway? Second, is the triggering of IGF-1 secretion mediated by $\mathrm{Ca}^{2+}$ binding to Syt 10 (but not to the synaptotagmins normally implicated in neuropeptide secretion) dependent on complexins similar to neurotransmitter secretion and chromaffin granule exocytosis induced by $\mathrm{Ca}^{2+}$ binding to Syt1, Syt2, Syt7, or Syt9?

Our data show that the vesicles mediating IGF-1 secretion are distinct in location and size from those mediating neuropeptide secretion (Figs. 1,2) but that the exocytosis of these IGF-1-containing vesicles is nevertheless dependent on complexins (Figs. 3-10). Moreover, our data demonstrate that complexin functions in IGF-1 secretion as an activator that enables rapid $\mathrm{Ca}^{2+}$-triggered exocytosis of IGF-1 containing vesicles. Thus, olfactory bulb neurons (most likely mitral neurons) generate two classes of peptidergic secretory vesicles whose $\mathrm{Ca}^{2+}$-triggered exocytosis depends on different isoforms of synaptotagmins but nevertheless uniformly requires complexins.

The evidence for our conclusions are as follows. (1) Immunocytochemically, Syt10 and IGF-1 are localized to the same secretory vesicles in neurons, whereas Syt1 and the LDCV markers ANF and phogrin are localized to a different class of secretory vesicles (Figs. 1, 2). (2) Morphologically, vesicles containing Syt10 and IGF-1 are significantly larger (cumulative distribution analysis, Kolmogorov-Smirnov test, $p<$ 0.01 ) than vesicles containing Syt1, ANF, and phogrin (Fig. 1). (3) In both olfactory bulb and cortical neurons, KD of complexin increased spontaneous mini release but decreased evoked neurotransmitter release, whereas only in olfactory bulb neurons did KD of complexin change the $C_{\mathrm{m}}$ and $R_{\mathrm{m}}$, consistent with a change in IGF-1 secretion (Figs. 3, 4). (4) Direct analysis of IGF-1 secretion revealed that the complexin $\mathrm{KD}$ severely impaired $\mathrm{Ca}^{2+}$-triggered IGF-1 exocytosis (Fig. 5). (5) Comparison of the $\mathrm{Ca}^{2+}$ dependence of neurotransmitter release and IGF-1 secretion revealed a similar $\mathrm{Ca}^{2+}$ dependence of exocytosis (Fig. 6). (6) Optical analyses of the effect of the complexin KD on the kinetics of IGF-1 exocytosis monitored via pHluorin-tagged Syt 10 demonstrated that the complexin KD broadly suppressed exocytosis (Figs. 7, 8). (7) Structure-function studies of complexin revealed that the activating role of complexin is essential for both neurotransmitter release and IGF-1 exocytosis (Figs. 9, 10).

Based on these data, we conclude that olfactory bulb neurons contain at least two independent and distinct pathways of $\mathrm{Ca}^{2+}$

$\leftarrow$

neurons at DIV14 -DIV16. Cultured olfactory bulb neurons were infected with control lentivirus or complexin KD (Cpx KD) lentiviruses expressing GFP only or GFP with superclamp or poorclamp complexin-1. $\boldsymbol{D}, C_{\mathrm{m}}$ (left) and $R_{\mathrm{m}}$ (right) of the mitral/tufted neurons examined in $\boldsymbol{B}$ and $\boldsymbol{C}$. $\boldsymbol{E}$, Measurements of IGF-1 secretion by cultured olfactory bulb neurons after incubation in 5 or 15 $\mathrm{mm} \mathrm{K}^{+}$for $1 \mathrm{~h}$ at DIV7-DIV8. Neurons were infected with lentiviruses as described in $\boldsymbol{B}$ and $\boldsymbol{C}$. Data shown are means \pm SEMs; numbers of cells/independent cultures $(\boldsymbol{C}, \boldsymbol{D})$ or just cultures $(\boldsymbol{E})$ are depicted in the bars. Statistical significance was assessed by Student's $t$ test, comparing the various $\mathrm{Cpx}$ KD conditions with the control condition except when indicated otherwise $\left({ }^{*} p<\right.$ $\left.0.05 ;{ }^{* *} p<0.01 ;{ }^{* * *} p<0.001\right)$. 
regulated polypeptide secretion: (1) a previously characterized LDCV pathway for neuropeptide secretion using Syt1 as a $\mathrm{Ca}^{2+}$ sensor (Walch-Solimena et al., 1993; Zhu et al., 2007) and (2) a novel pathway for IGF-1 secretion using Syt10 as a $\mathrm{Ca}^{2+}$ sensor (Cao et al., 2011). Both pathways are dependent on complexins, despite the fact that Syt1 and Syt10 are functionally distinct and non-redundant (Cao et al., 2011). Thus, complexins may generally cooperate with synaptotagmins in exocytosis and not only function as cofactors for Syt1-dependent exocytosis in synaptic and chromaffin exocytosis (Reim et al., 2001; Xue et al., 2007; Cai et al., 2008; Maximov et al., 2009), suggesting a much broader role in exocytosis than previously envisioned. Thus, the present data indicate that the phenotype of genetic complexin manipulations in mice, flies, and worms may be attributable to a general if partial impairment of multiple types of exocytosis. The general role of complexins in exocytosis is likely to be primarily as a positive activator of SNARE complexes before fusion-pore opening because this function appears to be more essential than the clamping function of complexin in synaptic vesicle exocytosis (Yang et al., 2010) and IGF-1 exocytosis (Figs. 9, 10). It should be noted, however, that complexin-different from synaptotagmin-does not seem to be absolutely required for neurotransmitter release or IGF-1 exocytosis, even when analyzed in double complexin-1/2 knock-out neurons (Reim et al., 2001). Thus, complexin acts more as a cofactor for synaptotagmins that improves the secretory reaction than as a building block of the secretory machinery.

Interestingly, the clamping activity of complexin seems to have no significant role in IGF-1 secretion, although it appears to exert a significant control of neurotransmitter release at synapses. It is possible that the clamping function of complexin does not play a major role in controlling IGF-1 exocytosis or that the rate of spontaneous IGF-1 exocytosis is too small to allow detection of spontaneous IGF-1 release events even after unclamping. The sensitivity of IGF-1 ELISAs is much lower than that of mEPSC measurements that allow detection of single-vesicle exocytosis events, strongly supporting the second hypothesis.

Our results complement recent findings that complexin is required for postsynaptic AMPA receptor exocytosis triggered by LTP and suggest that postsynaptic regulated exocytosis may also be dependent on a synaptotagmin (Ahmad et al., 2012). Furthermore, given the fact that complexin and at least Syt14, Syt15, and Syt16 appear to be universally expressed in all cells at low levels (McMahon et al., 1995; Fukuda, 2003a,b; Herrero-Turrión et al., 2006), our results suggest that a complexin/synaptotagmindependent pathway may operate in all cells to mediate an as yet unidentified type of exocytosis that could be regulated by a signal different from $\mathrm{Ca}^{2+}$. The universal role for complexin in exocytosis thus emerging is consistent with the evolutionary conservation of complexins and synaptotagmins in all animals, including sponges, and suggests that manipulating complexin function may be a general approach to influence regulated exocytosis in cells.

Why do olfactory bulb neurons develop a specific, activitydependent pathway of IGF-1 exocytosis? A first clue to this question came from studies demonstrating that IGF-1 performs an essential role in the continuous activity-dependent assembly of the neural circuitry of the olfactory bulb, which needs to be rewired throughout life because of adult neurogenesis of granule cells (Pixley et al., 1998; Vicario-Abejón et al., 2003; Scolnick et al., 2008; Hurtado-Chong et al., 2009). Moreover, a recent study revealed that neuronal diversity in the olfactory bulb may in part result from the activity-dependent adaptation of a neuron to the local neural circuits (Angelo et al., 2012). However, the underlying molecular mechanisms are unclear. Our results may explain how activity adjusts the properties of the neurons in the circuitry of the olfactory bulb. In the olfactory bulb, IGF-1 secreted from a mitral cell may, in a paracrine manner, only activate adjacent mitral cells sharing an identical glomerulus while leaving other, more distant, mitral cells unaffected. Because IGF-1 has been widely implicated in a variety of neuronal and circuit functions (Blair and Marshall 1997; Man et al., 2000; Wang and Linden, 2000; Ramsey et al., 2005; Tropea et al., 2006; Kim et al., 2007; Xing et al., 2007), our data suggest that the $\mathrm{Ca}^{2+}$-triggered IGF-1 exocytosis mediated by complexins and synaptotagmin may be involved in the regulation of mitral cell diversity in olfactory bulb. Moreover, similar mechanisms could potentially operate in other brain areas, linking activity-dependent exocytosis to the development of specific neuronal properties and neural circuits.

\section{References}

Ahmad M, Polepalli JS, Goswami D, Yang X, Kaeser-Woo YJ, Südhof TC, Malenka RC (2012) Postsynaptic complexin controls AMPA receptor exocytosis during LTP. Neuron 73:260-267. CrossRef Medline

Angelo K, Rancz EA, Pimentel D, Hundahl C, Hannibal J, Fleischmann A, Pichler B, Margrie TW (2012) A biophysical signature of network affiliation and sensory processing in mitral cells. Nature 488:375-378. CrossRef Medline

Blair LA, Marshall J (1997) IGF-1 modulates N and L calcium channels in a PI 3-kinase-dependent manner. Neuron 19:421-429. CrossRef Medline

Bolte S, Cordelières FP (2006) A guided tour into subcellular colocalization analysis in light microscopy. J Microsc 224:213-232. CrossRef Medline

Bracher A, Kadlec J, Betz H, Weissenhorn W (2002) X-ray structure of a neuronal complexin-SNARE complex from squid. J Biol Chem 277: 26517-26523. CrossRef Medline

Burke NV, Han W, Li D, Takimoto K, Watkins SC, Levitan ES (1997) Neuronal peptide release is limited by secretory granule mobility. Neuron 19:1095-1102. CrossRef Medline

Cai H, Reim K, Varoqueaux F, Tapechum S, Hill K, Sørensen JB, Brose N, Chow RH (2008) Complexin II plays a positive role in $\mathrm{Ca}^{2+}$-triggered exocytosis by facilitating vesicle priming. Proc Natl Acad Sci U S A 105: 19538-19543. CrossRef Medline

Cao P, Maximov A, Südhof TC (2011) Activity-dependent IGF-1 exocytosis is controlled by the $\mathrm{Ca}^{2+}$-sensor synaptotagmin-10. Cell 145:300-311. CrossRef Medline

Chen X, Tomchick DR, Kovrigin E, Ara ç D, Machius M, Südhof TC, Rizo J (2002) Three-dimensional structure of the complexin/SNARE complex. Neuron 33:397-409. CrossRef Medline

Cheng TW, Gong Q (2009) Secreted TARSH regulates olfactory mitral cell dendritic complexity. Eur J Neurosci 29:1083-1095. CrossRef Medline

Cho RW, Song Y, Littleton JT (2010) Comparative analysis of Drosophila and mammalian complexins as fusion clamps and facilitators of neurotransmitter release. Mol Cell Neurosci 45:389-397. CrossRef Medline

Dodge FA Jr, Rahamimoff R (1967) Co-operative action a calcium ions in transmitter release at the neuromuscular junction. J Physiol 193:419432. Medline

Fernández-Chacón R, Königstorfer A, Gerber SH, García J, Matos MF, Stevens CF, Brose N, Rizo J, Rosenmund C, Südhof TC (2001) Synaptotagmin I functions as a calcium regulator of release probability. Nature 410 : 41-49. CrossRef Medline

Fukuda M (2003a) Molecular cloning, expression, and characterization of a novel class of synaptotagmin (Syt XIV) conserved from Drosophila to humans. J Biochem 133:641-649. CrossRef Medline

Fukuda M (2003b) Molecular cloning and characterization of human, rat, and mouse synaptotagmin XV. Biochem Biophys Res Commun 306:64-71. CrossRef Medline

Gentet LJ, Stuart GJ, Clements JD (2000) Direct measurement of specific membrane capacitance in neurons. Biophys J 79:314-320. CrossRef Medline

Giraudo CG, Eng WS, Melia TJ, Rothman JE (2006) A clamping mechanism involved in SNARE-dependent exocytosis. Science 313:676-680. CrossRef Medline

Giraudo CG, Garcia-Diaz A, Eng WS, Yamamoto A, Melia TJ, Rothman JE 
(2008) Distinct domains of complexins bind SNARE complexes and clamp fusion in vitro. J Biol Chem 283:21211-21219. CrossRef Medline

Giraudo CG, Garcia-Diaz A, Eng WS, Chen Y, Hendrickson WA, Melia TJ, Rothman JE (2009) Alternative zippering as an on-off switch for SNARE-mediated fusion. Science 323:512-516. CrossRef Medline

Grabner CP, Fox AP (2006) Stimulus-dependent alterations in quantal neurotransmitter release. J Neurophysiol 96:3082-3087. CrossRef Medline

Gustavsson N, Han W (2009) Calcium-sensing beyond neurotransmitters: functions of synaptotagmins in neuroendocrine and endocrine secretion. Biosci Rep 29:245-259. CrossRef Medline

Herrero-Turrión MJ, Fukuda M, Mollinedo F (2006) Cloning and genomic characterization of sytdep, a new synaptotagmin XIV-related gene. Biochem Biophys Res Commun 340:386-394. CrossRef Medline

Hobson RJ, Liu Q, Watanabe S, Jorgensen EM (2011) Complexin maintains vesicles in the primed state in C. elegans. Curr Biol 21:106-113. CrossRef Medline

Huntwork S, Littleton JT (2007) A complexin fusion clamp regulates spontaneous neurotransmitter release and synaptic growth. Nat Neurosci 10: 1235-1237. CrossRef Medline

Hurtado-Chong A, Yusta-Boyo MJ, Vergaño-Vera E, Bulfone A, de Pablo F, Vicario-Abejón C (2009) IGF-I promotes neuronal migration and positioning in the olfactory bulb and the exit of neuroblasts from the subventricular zone. Eur J Neurosci 30:742-755. CrossRef Medline

Kaeser-Woo YJ, Yang X, Südhof TC (2012) C-terminal complexin sequence is selectively required for clamping and priming but not for $\mathrm{Ca}^{2+}$ triggering of synaptic exocytosis. J Neurosci 32:2877-2885. CrossRef Medline

Kim MJ, Futai K, Jo J, Hayashi Y, Cho K, Sheng M (2007) Synaptic accumulation of PSD-95 and synaptic function regulated by phosphorylation of serine-295 of PSD-95. Neuron 56:488-502. CrossRef Medline

Krishnakumar SS, Radoff DT, Kümmel D, Giraudo CG, Li F, Khandan L, Baguley SW, Coleman J, Reinisch KM, Pincet F, Rothman JE (2011) A conformational switch in complexin is required for synaptotagmin to trigger synaptic fusion. Nat Struct Mol Biol 18:934-940. CrossRef Medline

Li F, Pincet F, Perez E, Giraudo CG, Tareste D, Rothman JE (2011) Complexin activates and clamps SNAREpins by a common mechanism involving an intermediate energetic state. Nat Struct Mol Biol 18:941-946. CrossRef Medline

Malsam J, Seiler F, Schollmeier Y, Rusu P, Krause JM, Söllner TH (2009) The carboxy-terminal domain of complexin I stimulates liposome fusion. Proc Natl Acad Sci U S A 106:2001-2006. CrossRef Medline

Man HY, Lin JW, Ju WH, Ahmadian G, Liu L, Becker LE, Sheng M, Wang YT (2000) Regulation of AMPA receptor-mediated synaptic transmission by clathrin-dependent receptor internalization. Neuron 25:649-662. CrossRef Medline

Martin JA, Hu Z, Fenz KM, Fernandez J, Dittman JS (2011) Complexin has opposite effects on two modes of synaptic vesicle fusion. Curr Biol 21:97105. CrossRef Medline

Maximov A, Tang J, Yang X, Pang ZP, Südhof TC (2009) Complexin controls the force transfer from SNARE complexes to membranes in fusion. Science 323:516-521. CrossRef Medline

McMahon HT, Missler M, Li C, Südhof TC (1995) Complexins: cytosolic proteins that regulate SNAP receptor function. Cell 83:111-119. CrossRef Medline

Pang ZP, Xu W, Cao P, Südhof TC (2010) Calmodulin suppresses synaptotagmin-2 transcription in cortical neurons. J Biol Chem 285: 33930-33939. CrossRef Medline

Pfeffer LA, Brisson BK, Lei H, Barton ER (2009) The insulin-like growth factor IGF-I E-peptides modulate cell entry of the mature IGF-I protein. Mol Biol Cell 20:3810-3817. CrossRef Medline

Pixley SK, Dangoria NS, Odoms KK, Hastings L (1998) Effects of insulinlike growth factor 1 on olfactory neurogenesis in vivo and in vitro. Ann N Y Acad Sci 855:244-247. CrossRef Medline

Ramsey MM, Adams MM, Ariwodola OJ, Sonntag WE, Weiner JL (2005) Functional characterization of des-IGF-1 action at excitatory synapses in the CA1 region of rat hippocampus. J Neurophysiol 94:247-254. CrossRef Medline

Reim K, Mansour M, Varoqueaux F, McMahon HT, Südhof TC, Brose N, Rosenmund C (2001) Complexins regulate a late step in $\mathrm{Ca}^{2+}$ dependent neurotransmitter release. Cell 104:71-81. CrossRef Medline

Reim K, Wegmeyer H, Brandstätter JH, Xue M, Rosenmund C, Dresbach T, Hofmann K, Brose N (2005) Structurally and functionally unique com- plexins at retinal ribbon synapses. J Cell Biol 169:669-680. CrossRef Medline

Schaub JR, Lu X, Doneske B, Shin YK, McNew JA (2006) Hemifusion arrest by complexin is relieved by $\mathrm{Ca}^{2+}$-synaptotagmin I. Nat Struct Mol Biol 13:748-750. CrossRef Medline

Schonn JS, Maximov A, Lao Y, Südhof TC, Sørensen JB (2008) Synaptotagmin-1 and -7 are functionally overlapping $\mathrm{Ca}^{2+}$ sensors for exocytosis in adrenal chromaffin cells. Proc Natl Acad Sci U S A 105: 3998-4003. CrossRef Medline

Scolnick JA, Cui K, Duggan CD, Xuan S, Yuan XB, Efstratiadis A, Ngai J (2008) Role of IGF signaling in olfactory sensory map formation and axon guidance. Neuron 57:847-857. CrossRef Medline

Seiler F, Malsam J, Krause JM, Söllner TH (2009) A role of complexin-lipid interactions in membrane fusion. FEBS Lett 583:2343-2348. CrossRef Medline

Sørensen JB, Fernández-Chac ón R, Südhof TC, Neher E (2003) Examining synapto-tagmin 1 function in dense core vesicle exocytosis under direct control of $\mathrm{Ca}^{2+}$. J Gen Physiol 122:265-276. CrossRef Medline

Strenzke N, Chanda S, Kopp-Scheinpflug C, Khimich D, Reim K, Bulankina AV, Neef A, Wolf F, Brose N, Xu-Friedman MA, Moser T (2009) Complexin-I is required for high-fidelity transmission at the endbulb of Held auditory synapse. J Neurosci 29:7991-8004. CrossRef Medline

Südhof TC, Rothman JE (2009) Membrane fusion: grappling with SNARE and SM proteins. Science 323:474-477. CrossRef Medline

Sugita S, Shin OH, Han W, Lao Y, Südhof TC (2002) Synaptotagmins form a hierarchy of exocytotic $\mathrm{Ca}(2+)$ sensors with distinct $\mathrm{Ca}^{2+}$ affinities. EMBO J 21:270-280. CrossRef Medline

Tang J, Maximov A, Shin OH, Dai H, Rizo J, Südhof TC (2006) A complexin/ synaptotagmin 1 switch controls fast synaptic vesicle exocytosis. Cell 126:1175-1187. CrossRef Medline

Tropea D, Kreiman G, Lyckman A, Mukherjee S, Yu H, Horng S, Sur M (2006) Gene expression changes and molecular pathways mediating activity-dependent plasticity in visual cortex. Nat Neurosci 9:660-668. CrossRef Medline

Vicario-Abejón C, Yusta-Boyo MJ, Fernández-Moreno C, de Pablo F (2003) Locally born olfactory bulb stem cells proliferate in response to insulinrelated factors and require endogenous insulin-like growth factor-I for differentiation into neurons and glia. J Neurosci 23:895-906. Medline

Walch-Solimena C, Takei K, Marek KL, Midyett K, Südhof TC, De Camilli P, Jahn R (1993) Synaptotagmin: a membrane constituent of neuropeptidecontaining large dense-core vesicles. J Neurosci 13:3895-3903. Medline

Wang YT, Linden DJ (2000) Expression of cerebellar long-term depression requires postsynaptic clathrin-mediated endocytosis. Neuron 25:635-647. CrossRef Medline

Wasmeier C, Burgos PV, Trudeau T, Davidson HW, Hutton JC (2005) An extended tyrosine-targeting motif for endocytosis and recycling of the dense-core vesicle membrane protein phogrin. Traffic 6:474-487. CrossRef Medline

Winkler H, Fischer-Colbrie R (1998) Regulation of the biosynthesis of large dense-core vesicles in chromaffin cells and neurons. Cell Mol Neurobiol 18:193-209. CrossRef Medline

Xing C, Yin Y, Chang R, Gong X, He X, Xie Z (2007) Effects of insulin-like growth factor 1 on synaptic excitability in cultured rat hippocampal neurons. Exp Neurol 205:222-229. CrossRef Medline

Xu J, Mashimo T, Südhof TC (2007) Synaptotagmin-1, -2, and -9: $\mathrm{Ca}^{2+}$ sensors for fast release that specify distinct presynaptic properties in subsets of neurons. Neuron 54:567-581. CrossRef Medline

Xue M, Reim K, Chen X, Chao HT, Deng H, Rizo J, Brose N, Rosenmund C (2007) Distinct domains of complexin I differentially regulate neurotransmitter release. Nat Struct Mol Biol 14:949-958. CrossRef Medline

Xue M, Lin YQ, Pan H, Reim K, Deng H, Bellen HJ, Rosenmund C (2009) Tilting the balance between facilitatory and inhibitory functions of mammalian and Drosophila Complexins orchestrates synaptic vesicle exocytosis. Neuron 64:367-380. CrossRef Medline

Xue M, Craig TK, Xu J, Chao HT, Rizo J, Rosenmund C (2010) Binding of the complexin $\mathrm{N}$ terminus to the SNARE complex potentiates synapticvesicle fusogenicity. Nat Struct Mol Biol 17:568-575. CrossRef Medline

Yang X, Kaeser-Woo YJ, Pang ZP, Xu W, Südhof TC (2010) Complexin clamps asynchronous release by blocking a secondary $\mathrm{Ca}^{2+}$ sensor via its accessory alpha helix. Neuron 68:907-920. CrossRef Medline

Yoon TY, Lu X, Diao J, Lee SM, Ha T, Shin YK (2008) Complexin and $\mathrm{Ca}^{2+}$ 
stimulate SNARE-mediated membrane fusion. Nat Struct Mol Biol 15: 707-713. CrossRef Medline

Zahn TR, Macmorris MA, Dong W, Day R, Hutton JC (2001) IDA-1, a Caenorhabditis elegans homolog of the diabetic autoantigens IA-2 and phogrin, is expressed in peptidergic neurons in the worm. J Comp Neurol 429:127-143. CrossRef Medline
Zhu D, Zhou W, Liang T, Yang F, Zhang RY, Wu ZX, Xu T (2007) Synaptotagmin I and IX function redundantly in controlling fusion pore of large dense core vesicles. Biochem Biophys Res Commun 361:922-927. CrossRef Medline 